\title{
Implementation Plan for Low-carbon Resilient City towards Sustainable Development Goals: Challenges and Perspectives
}

\author{
Xiaoni He${ }^{1}$, Merrisa Lin², Tse-Lun Chen ${ }^{3}$, Bowei Liu ${ }^{4}$, Po-Chih Tseng ${ }^{3}$, Wenzhi Cao ${ }^{5}$, \\ Pen-Chi Chiang ${ }^{3 *}$ \\ ${ }^{1}$ Graduate School of Humanities and Social Sciences, University of Melbourne, Parkville VIC 3052, Australia \\ ${ }^{2}$ Faculty of Social Science, The Chinese University of Hong Kong, Hong Kong, China \\ ${ }^{3}$ Graduate Institute of Environmental Engineering, National Taiwan University, Taipei 10617, Taiwan \\ ${ }^{4} \mathrm{~W}$ Booth School of Engineering Practice and Technology, McMaster University, Hamilton, ON L8S 4L8, Canada \\ ${ }^{5}$ Key Laboratory of the Ministry of Education for Coastal Wetland Ecosystems, College of the Environment and Ecology, \\ Xiamen University, Xiamen 361102, China
}

\begin{abstract}
Mitigation and adaptation are two climate approaches for reducing risks and preparing for hazards caused by the climate change. The development of low-carbon resilient cities must integrates mitigation and adaptation, which has great potential in decarbonization and natural disaster prevention However, limited studies have focused on systematizing the low-carbon resilience approach. To address this problem, this study aims to develop an implementation plan of low-carbon resilient cities. A theoretical framework is designed to analyze integrated strategies and key performance indicators for low-carbon resilient cities. Two related schemes, the "SIEGE" scheme and " $5 \mathrm{P}$ " scheme, are provided to assist in the planning and governance. Challenges for implementing a low-carbon resilience approach are discussed from institutional, regulatory, financial, technical and communication perspectives. Guided by the theoretical frameworks and practical strategies, cities will be able to move towards social equality, energy-efficiency, hazards preparedness, governing-effectiveness and innovation.
\end{abstract}

Keywords: Low-carbon resilient city; Sustainable Development Goals (SDGs); Climate change.

\section{INTRODUCTION}

With rapid economic growth in the past century, environmental problems resulting from the pursuit of prosperity have posed severe threats to society. Natural resource depletion, environmental quality deterioration, and climate change are three significant global challenges which all people should attribute significance and awareness. To strengthen knowledge and measures to combat these challenges, the United Nations proposed 17 Sustainable Development Goals in 2015. This indicates 196 member countries around the world will be making efforts to move towards a better world in terms of social, environmental, and economic aspects. Urban cities, as the base of human activities, in turn play a significant role in responding to these global challenges and achieving sustainable development goals. Mitigation and adaptation are two streams of climate

\footnotetext{
${ }^{*}$ Corresponding author.

Tel.: +886-2-23622510; Fax: +886-2-23661642

E-mail address: pcchiang@ntu.edu.tw
}

approaches that governments commonly adopt and implement separately. Mitigation refers to decarbonization practices, while adaptation refers to the efforts made for risk and disaster prevention. However, integrating the two approaches, can be regarded as developing low-carbon resilience, can create great opportunities to increase efficiency and maximize benefits.

\section{Global Challenges}

In recent decades, our world has been facing an increasing number of complicated challenges. Environmental instability has become one of the biggest concerns. The World Economic Forum (WEF) highlights the following five critical global issues in the Global Risks Report of 2019: economic vulnerabilities, geopolitical tensions, societal and political strains, environmental fragilities, and technological instabilities (WEF, 2019). Further, the data reflects that environmental risks play dominant roles in influencing the results of the Global Risks Perception Survey (GRPS), accounting for more than half of the top five global risks including both the likelihood and impacts of the risks (WEF, 2019). This implies the importance of probing into environmental problems and the interconnection between environment-related risks as well as social-oriented aspects of global challenges. 
Natural Resource Depletion

According to the Global Footprint Network (GFN), the consumption of natural resources from humanity is moving 1.75 times faster than our ecosystems can regenerate (UNFCCC, 2019). As a result, available natural resources for humans are in severe shortage. Today, merely less than $1 \%$ of freshwater is accessible for human use (Denchak, 2018). The daily oil consumption has overrun twice as much as the amount 50 years ago, and almost half the extractable oil in known fields has been depleted (IOGP, 2017; Cooper and Johnson, 2018). The earth's known natural gas reserves could run out in 52 years (BP, 2016). The total recoverable reserves of coal were estimated to be 1,136 billion short tons in 2015 (EIA, 2015). Unless appropriate measures are taken, the natural resources that humankind is very dependent upon could sustain humanity for merely 50 to 100 years (BP, 2016).

One of the crucial reasons for the natural resource depletion is the extreme unsustainability of current business models and energy consumption patterns, focused more on short-term interests without critical consideration of longterm needs and the impact of over-exploitation (Lundberg, 2019). In addition to the depletion, the extravagant use of natural resources by human activities causes half of the global greenhouse gas (GHG) emissions (UNEP, 2018). The International Energy Agency addresses the fact that global carbon emissions climbed to a record of 33.1 billion tons in 2018 (Lannin, 2019). The higher use of fossil fuel sources accounts for one-third of the total growth of carbon emissions. Despite the critical nature of natural resource depletion, low awareness of environmental issues has contributed to more severe environmental challenges (Yu et al., 2016). Therefore, the necessity of taking action to transform the traditional energy pattern and economic model is now more urgent than ever.

\section{Environmental Quality Degradation}

Natural resource depletion also leads to environmental quality degradation. The environment is the composition of everything that surrounds us, and natural resources are the majority of what surrounds us: water, soil, air, coal, natural gas, oil, and minerals. However, they are not only resources to be used for human activities and society's prosperity but also are the essential factors influencing the resilience function of ecosystems, namely the capacity to resist hazards and natural disasters. Therefore, the depletion of nature resources clearly demonstrates that our environment is becoming more vulnerable.

Worsening air quality is additionally a threat to human lives. It is estimated that global deaths caused by indoor air pollution is 3.8 million people annually (UNEP, 2018). In underdeveloped countries, $97 \%$ of cities fail to meet air quality standards (UNEP, 2018). Degraded waste quality is another significant urban issue. More than $30 \%$ of the most important $\mathrm{t}$ groundwater systems around the world are in great distress (Ritchie and Roser, 2017). Almost 50\% of rivers and streams have been determined as unsuitable for human consumption following their pollution (Denchak, 2018). Soil quality is also declining and losing the ability to provide the earth with significant nutrients. Over $30 \%$ of soil on the planet has been degraded, and $50 \%$ of topsoil has vanished in the last 150 years (WWF, 2018). Moreover, more than $75 \%$ of land areas are substantially degraded, which undermines the well-being of 3.2 billion people (Leahy, 2018; Scholes et al., 2018). From the above statistics, ecosystems, habitats as well as biodiversity on earth are being harshly decimated; that is, our planet is becoming severely unstable and vulnerable.

\section{Climate Change}

A 2018 IPBES report regarding climate change shows that land degradation and GHG emissions are two significant factors resulting in climate change (Scholes et al., 2018). It is estimated that in 2017 global warming induced by human activities rose to about $1^{\circ} \mathrm{C}$ compared to pre-industrial levels (IPCC, 2018b). The temperature dataset also records that a significant number of regions worldwide have experienced, on average more than a $1.5^{\circ} \mathrm{C}$ increase in temperature (IPCC, 2018a). According to the United Nations Environment Assembly, climate change, and the extravagance of natural resources are two major environmental challenges faced by the planet and humankind (Lundberg, 2019).

In the past few years, humankind has witnessed intensive natural catastrophes resulting from global warming, such as wildfires, droughts, and floods that accordingly lead to significant food shortages and economic losses (IPCC, 2018a). In 2018, climate change contributed to a 131.7-billion-dollar loss triggered by natural disasters. This is 2.5 times higher than what it was 20 years ago (CRED, 2019). Additionally, a rising number of climate refugees have been documented in the past decade. In 2018 alone, 17.2 million people in 144 countries were displaced from their habitats because of disasters (IOM, 2019). Clearly, climate change viciously attacking public health. A significant number of deaths is recorded as a result of extreme heat increase, rising weatherrelated diseases, and changes in infection patterns (WHO, 2018). It is expected that an additional five million people will die from the hazards and illnesses resulting from climate change from 2030 to 2050 (WHO, 2018). Climate change has an unpredictable impact on human societies and the environment; it is, therefore, a critical time for humanity to take climate actions.

\section{Sustainable Development Goals}

Facing these unprecedented urgent challenges, the United Nations adopted 17 Sustainable Development Goals (SDGs) as part of the 2030 Agenda for Sustainable Development at the UN Summit in 2015. The 17 SDGs are supplemented by 169 targets and 232 indicators to measure progress. While every sustainable development goal has its own focus, they are interdependent to a large extent, holding the same vision to develop sustainability with economic, social, and environmental efforts.

To address the importance of low-carbon resilience (LCR) as well as to strengthen the idea of it, commonalities of SDGs and LCR are being investigated and coded in the following section. Based on the official list of sustainable development goals which states that all targets and indicators adopted by UN, "mitigation", "mitigate", "carbon", "CO 2 ", 
"GHG emission" and "fossil fuel" are coded as low-carbon relevance while "resilience", "resilient", "resiliency", "adaptation", "adapt" and "adoption" are coded as resilience relevance. As a result of cross-comparison between different indicators, tables of low carbon sustainable development goals (LCSDGs) and resilience sustainable development goals (RSDGs) are generated. Five SDGs are relevant to low carbon, while six SDGs are resilience-related (Appendix A and Appendix B).

The comparison of the two tables shows that SDG 9, SDG 11, and SDG 13 have both low carbon and resilience keywords (Fig. 1). Also, among 17 SDGs, only SDG 9 and SDG 11 mention "resilient" in the description of goals. Lowcarbon keywords have always been found in targets or indicators of RSDGs. It is therefore suggested that lowcarbon actions can assist in achieving resilience as well as reflecting the performance of RSDGs. Further developing a set of low-carbon resilient strategies, relevant, sustainable development goals, targets, and indicators will be discussed in the following sections.

\section{Low Carbon and Resilience}

Cities are the primary sources of greenhouse gas emissions, contributing to $70 \%$ of global $\mathrm{CO}_{2}$ emissions (IEA, 2016). Urban cities involve human activities and heavy industries that are very dependent on energy and natural sources, which indicates the crucial role of cities in the course of carbon reduction. Based on the challenges above, urban cities have two major steams of action to focus. One is "mitigation", which means focusing on reducing greenhouse gas emission and transforming to low-carbon development. The other stream is to plan and build "resilience" as the response to unavoidable climate change impacts, defined as "adaptation" (Harford and Raftis, 2018). Aiming to develop an integrated approach for sustainable transformation of cities, scholars suggested the idea of "low carbon resilience", which is a more effective and efficient method compared to coping with the issues separately (Harford and Raftis, 2018).

Resilience, as a formal ecological concept, was first proposed by Holling in 1973. It is defined as the capacity to absorb instability and adapt changes. The definitions can be classified into two categories. One is outcome-oriented which focuses on the result of the implementation, such as recovery

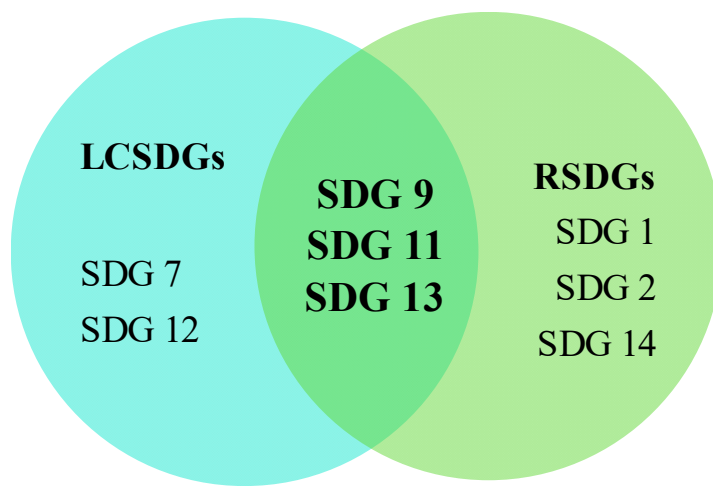

Fig. 1. The overlap between low carbon SDGs and resilient SDGs. scale and time. The other stream is process-oriented, which emphasizes the ability to adapt to hazardous situations (Gilbert, 2010). In the indexes proposed by Godschalk (2003), components of resilience include "diversity", "redundancy", "robustness", "recovery", "adaptation" and "ability to learn and translate." "Diversity" refers to multi-facets mechanisms in a city which enables it to critically solve problems with various skills while "redundancy" indicates the additional tangible or intangible resources that are available when emergencies occur. "Robustness" is the process-oriented characteristic that highlights the "capability of resistance" while "recovery" features the "capability of recovery" (ARUP, 2014). "Adaptation" is defined as the capability to adjust to new conditions through self-adjustments. Finally, the "ability to learn and translate" requires an individual to learn from experiences and further create as well as innovate.

\section{INTERNATIONAL MOVEMENT ON LOW- CARBON RESILIENT CITY TOWARDS SDGS}

In order to understand the historical background and seek the conceptual roots of urban planning towards sustainable development, the trajectory of the international movement on low-carbon resilient cities is analyzed, which is demonstrated in Fig. 2. The concepts about city, including healthy city, garden city, resilient city, eco-city, sustainable city, green city, low-carbon city and low-carbon resilient city, are briefly explained and discussed in this section.

\section{Healthy City}

Since the beginning of the Industrial Revolution in the 1760s, the energy consumption patterns of humans have dramatically changed. With the rapid growth of the economy, urbanization, and population, the current inadequate sanitation facilities bring severe threats to urban environments and public health. Natural resources were being exploited by a group of people who obtained the privilege to access, and rapid economic growth widened the gap between the rich and poor, which further resulted in economic and social inequality. In its early stages, people tended to first notice the worsening social issues such as poverty, diseases, and deteriorating public health. Recognizing these problems in society, the idea of healthy cities was first proposed by Edwin Chadwick in the Report on the Sanitary Conditions of the Labouring Population of Great Britain in 1842. Using the term "healthy towns" and "healthy villages", Chadwick described a well-conditioned society that would be free of sanitation problems and income inequality (Chadwick, 1843; Awofeso, 2003).

Based on the report of Chadwick, the World Health Organization (WHO) started to practice the idea of "health villages" by launching the Health Cities program in 1986. It aims to improve our environments and to enhance harmony in cities physically as well as socially (WHO, 1998). Following the changing trend of the world, the goal of the Health Cities program is enriched by multidimensional targets such as environmental issues, social cohesion, and citizen participation (WHO, 2019a). With respect to developing a healthy social environment, the healthy city aims to enable people to mutually 


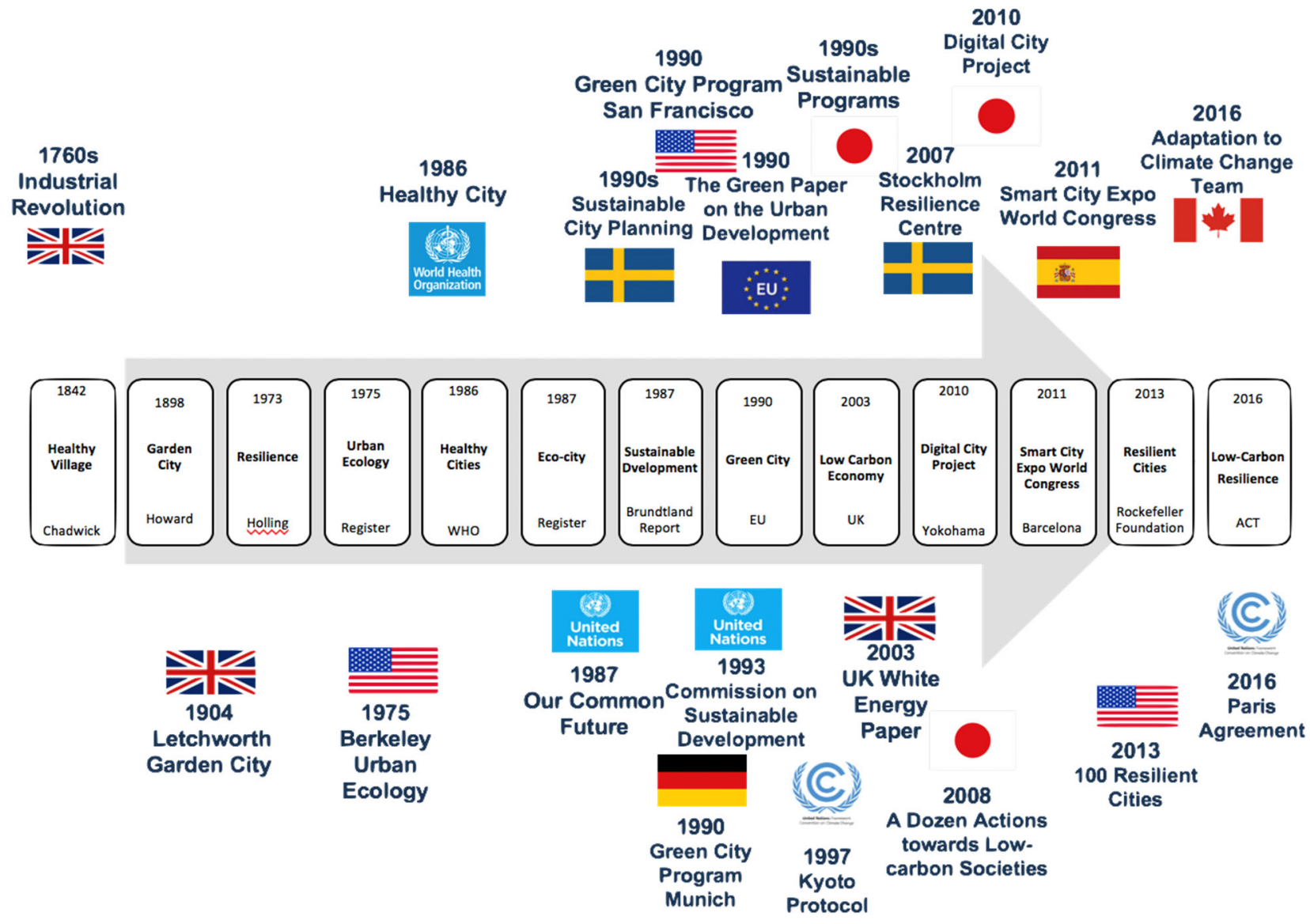

Fig. 2. Timeline of international movement towards low-carbon resilient cities.

support each other to improve living conditions, working conditions, public education, and democratic governance towards reducing social inequalities (Awofeso, 2003).

\section{Garden City}

Another scholar, Ebenezer Howard, also saw and studied the "illness" of cities in the $19^{\text {th }}$ century. The solution he proposed to diminish social and economic inequality was to build "garden cities", which was defined in his book "Tomorrow: A Peaceful Path to Real Reform," published in 1898. Howard advocated land-use reform through creating "green girdles" and "agricultural belts" surrounding big cities (Ward, 1990). To further reduce societal and economic inequality, Howard proposed the idea of appropriately distributing residential, industrial, and agricultural areas in the cities (Sharifi, 2016). Adding to an equitable distribution of the lands in the community, Garden City concept is generalized under the principle of cooperative economic enterprise between labors and capitals (Richert and Lapping, 1998).

Influenced by the work of Howard, London began to refer to the concept of "garden cities" in the London County Council in 1891 (Thomas, 1963). Influenced by the new focus, countries, cities, and citizens have begun to place greater importance on the role of public space and infrastructure since the 1900s (Müller and Mattissek, 2018). The concept of garden cities has stimulated urban planners to involve "green" in the urban planning context, which suggests the relationship between "garden city" and "green city". Some scholars perceive "garden city" as the initial "prototype" of the "green city" (Parsons and Schuyler, 2004).

\section{Resilient City}

In addition to societal and economic problems, concerns regarding the natural environment have been rising since the 1950 s. The origin of "resilience" can be traced back to the time when the first group of ecological scholars, including MacArthur (1955) and Lawton and Brown (1994), began to study environmental stability with an emphasis on biodiversity. Later in 1973, the idea of "resilience" was first systematically discussed by Crawford Stanley Holling. In his paper "Resilience and stability of ecological systems", Holling (1973) pointed out "the need for persistence" that ecological resilience focuses on, which was an extension of the previous view on stability. Since the 1980s, Holling (1973) has expanded the concept of resilience to engineering and management perspectives. Concurrently, the study on resilience was becoming popular because of the increasing public concerns about the environment and natural threats. An increasing number of scholars have been involved in a multi-disciplinary resilience study (Beigi, 2015). The attention of resilient cities has shifted to a broader spectrum of topics, including various aspects such as the social community network, urban systems education, and collaboration between professionals. It is widely believed that a city will be 
strengthened by adapting from disasters through a networked community system.

The concept of resilience has developed into the synthetic and operational level since the 21 st century (Beigi, 2015). In 2007, Stockholm Resilience Centre was founded with the vision to enhance socio-ecological cohesion and sustainably develop civilization (SRC, 2019). In 2013, the World Economic Forum Meeting set "Resilient Dynamism" as a topic of discussion (West, 2013). In the same year, the Rockefeller Foundation established the 100 Resilient Cities program to guide member cities toward resiliency goals to combat physical, economic, and societal challenges financially and logistically (Martín et al., 2018). The program has been acknowledged as a milestone in the operational roadmap of resilient cities. Until now, 97 cities around the world have been selected to the 100 Resilient Cities project, over 2600 initiatives have been undertaken, and more than three billion dollars have been invested to fund the resilient-oriented initiatives (Martín et al., 2018).

\section{Eco-city}

The concept of an "eco-city" originated in a foundation called "Urban Ecology" established by Richard Register in 1975, which targeted on transforming the city of Berkeley to an eco-city (Urban Ecologist, 2019). After more than a decade of practical effort, Register published a book titled "Eco-city Berkeley: Building Cities for a Heathy Future" in 1987. The book theorized the idea and discussed the transferability of the urban planning concept (Zhou and Williams, 2013). "Eco-city" was defined as "rebuilding cities in balance with nature" in the book. The notion of "nature" was described as the concept focusing more on environmental and ecological planning, and the idea of "balance" suggested consideration of economic, societal, and environmental equality. With an emphasis on both "nature" and "balance", the concept of social ecology is integrated with eco-city notion. Social ecology is a study examining the relationships that affect society and nature. It goes beyond the traditional view of protecting nature resources while stressing humans living harmoniously with natural environments (Roseland, 1997).

Register (1987) specified that the principles of urban planning solution of eco-city in Berkeley could be applied to other cities around the world. Since then, the idea of ecocities has raised significant awareness of environmental as well as ecological perspectives of city development. In 1990, the first International Ecocity Conference (now renamed as the Ecocity World Summit) was held in Berkeley, California. It focused on enhancing health and life equality of citizens as well as conserving the ecosystems. The summit has had significant influence, with more than 11,000 summit participants involved. Due to the establishment of the "eco-city" concept, resilience and adaption are determined as an important theme for ecocity development (Eberlein, 2018).

\section{Sustainable City}

In addition to the "eco-city" conceptualization, "sustainable development" was another trending environmental topic brought forward in the 1980s. The concept of "sustainable development" was derived from "Our Common Future" released by the Brundtland Commission, which is also known as the Brundtland Report in 1987. Although the Intergovernmental Conference for Rational Use and Conservation of the Biosphere (UNESCO) also mentioned "sustainable development" earlier in 1968, it merely emphasized the ecological aspect (Creech, 2012). By contrast, the Brundtland report bridged linkages between societal, economic, and environmental issues of "sustainable development" and, thus, was identified as a remarkable milestone in the environmental discussion. The Brundtland report advocated a pattern of development that can satisfy current needs and ensure regeneration for future requirements (Brundtland, 1987).

Since then, sustainable development has become conceptual guidance for urban planning, which motivates and inspires the emergence and development of sustainable cities. One of the milestone initiatives of sustainable cities is The Charter of European Sustainable Cities and Towns Towards Sustainability launched by the European Union in 1994 (De Jong et al., 2015). The initiative was adopted by more than 700 cities over the world (De Jong et al., 2015). One example is the Melbourne Principle for Sustainable Cities introduced in 2002 which provided a theoretical framework to guide cities toward sustainable development.

\section{Green City}

Before the 1980s, the conception of "green" in the urban context shared similar roots of "garden cities" (Parsons and Schuyler, 2004). In that period, governments stressed the usage of lands and green spaces when applying "green" approaches. Canadian Greenpeace initiative in 1987 and the Green Belt Movements of Kenya in 1977 represented the "green" concept during that time. Later on, the emergence of "eco-city" and "sustainable development" endowed new connotation to the term "green". In 1990, European Communities launched "the Green Paper on the Urban Development", guiding more cities to achieve sustainable development (Beatley, 2000). Intensifying the connection between "green" and "sustainability", numerous nongovernment organizations began to adopt the term "green cities" to demonstrate their vision towards sustainable development, such as European Green Cities (EGC) and Green Cities program of Organization for Economic Cooperation and Development (OECD) (Müller and Mattissek, 2018).

Today, the concept of "Green City" is regarded as an extension of sustainable development (Lewis, 2015; Pace et al., 2016). The European Landscape Contractors Association (ELCA) defines a "green city" as an environmental friendly place with a "sustainable green developing pattern in all disciplines" (ELCA, 2011). According to the explanation of the United Nations Environment Programme (UNEP), health, safety, high-quality environments, a green economy, and sustainable consumption are the primary goals of green cities (UNEP, 2011).

\section{Low-carbon City}

Since the $19^{\text {th }}$ century, humans have increasingly been concerned about environmental problems. Notwithstanding 
that the first academic research regarding the impact of rising carbon dioxide on air quality and ground temperature was published in 1895, low-carbon actions have not been practiced legitimately on the urban reformation level until 2003 when the government of the United Kingdom released The Energy White Paper with the purpose of developing a low carbon economy (De Jong et al., 2015). After the UK led the wave of the low carbon economy, more countries and cities started to move towards the development of low carbon cities. "Zero-carbon Eco-city Program" of Dongtan in 2005, "Low2No" (low-to-no carbon) project of Helsinki in 2006 and "A Dozen Actions towards Low-Carbon Societies" of Japan in 2008 are some examples of such economies.

In addition to the spontaneity of nations and cities, international conventions have been playing crucial roles in driving the construction of low-carbon cities. In 1997, the Kyoto Protocol as the first international treaty on low carbon was adopted by more than 150 countries in the United Nations Framework Convention on Climate Change (UNFCCC) Conference (Arrhenius, 1986; Yuan et al., 2011). The Protocol entered into force in 2005, and total participants rose to 192 in 2013. Two years later, the Paris Agreement replaced the Kyoto Protocol because of the reduced effectiveness of the Kyoto Protocol. The Paris Agreement binds participants to target mitigating global warming and urges the need to strengthen the implementation efforts.

\section{Low Carbon Resilient City}

With the expansion and popularity of low-carbon cities and resilient cities in the urban context, it is found that "low carbon" and "resilience" usually coexist in either international agreements or government mandates. The Energy White Paper published by the United Kingdom in 2003, as an example of low-carbon mandates, mentioned "resilience" in "Cleaner, Smart Energy" and "Energy Reliability" chapters. In the Paris Agreement, four of the Articles binding lowcarbon targets discuss resilience. As for resilience cities strategic planning, low carbon tends to be a complementary idea because carbon emission negatively impacts the vulnerability of climate change and cities.

Therefore, organizations began to put the two concepts together since the late 2000s. For instance, the Australian Government released "A low carbon and resilient urban future" in 2001. Nine least development countries have proclaimed their low-carbon cities development plans since 2009 (Fisher, 2013). The Scottish Cities Alliance published a report titled "Low Carbon Resilient Cities: Investment Opportunities for 'Better' Growth" in 2015. In Canada, the Adaptation to Climate Change Team (ACT) was built to explore opportunities and strategies for low-carbon resilience in 2016.

The low-carbon resilience report by ACT is the most systematic among the strategic paperwork formulated by the above organizations. The team develops an "integrated climate action approach," combining adaptation and mitigation, visualizing the idea through a conceptual process model and matrix (Harford and Raftis, 2018). The model demonstrates the interaction process of adaptation and mitigation, which also indicates the interaction between low carbon and resilience. Essentially, low carbon is a demonstration of mitigation, and resilience embodies the idea of adaptation. As Fig. 3 shows, combining the two ideas together has great potential to maximize the efficiency and effectiveness of climate actions.

\section{LCR STRATEGIES AND KEY PERFORMANCE INDICATORS (KPIS) TOWARDS SDGS}

Extending from previous sections regarding analyzing current environmental challenges and vulnerabilities, a development framework integrating a low-carbon approach and a resilience approach is introduced in this section. Aiming to conclude the most adaptive and efficient strategies as well as indicators for low-carbon resilient implementation towards SDGs, a development framework for selecting and integrating low-carbon resilient Strategies with Key Performance Indicators (KPIs) forming based on the aforementioned low-carbon resilient conceptual process model is presented in Fig. 4.

\section{Low-carbon Resilient Strategies}

In this subsection, the study focuses on developing strategies that integrate low-carbon and resilience. Through reviewing cities with leading low-carbon and resilience practices as well as strategic planning, it demonstrates that different organizations present or describe strategies in different ways. To find out the strategic commonality for better comparing and contrasting different cities' focuses, we highlight the vital keywords that best indicate the big idea or significant orientation of each strategy. This helps to compare and contrast the different focuses of cities. Based on the strategic keywords we generate, the controls and influence exerted by various governments and decisionmakers are analyzed, which can guide to design low-carbon resilience strategies with critical enhancements and instruments that work out best on the specific sector. The results are listed in the following Table 1.

After analyzing the sectors, strategies and enhancements, the following five strategies are proposed for cities to improve LCR development:

- Advocate low-carbon culture and lifestyle through public education and communication in the process of building social equality, community cohesion and cultural inclusiveness.

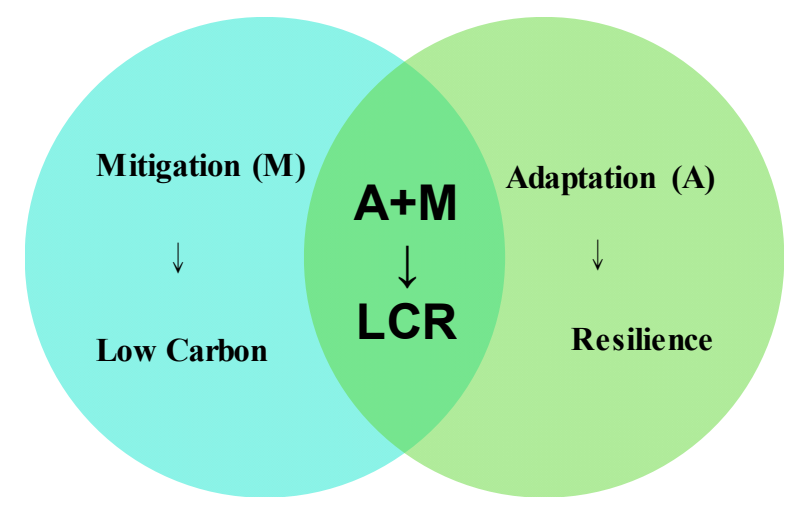

Fig. 3. Low carbon and resilience interaction. 
ENVIRONMENTAL ISSUES

1. Natural Resource Depletion

2. Environmental Quality Degradation

3. Climate Change

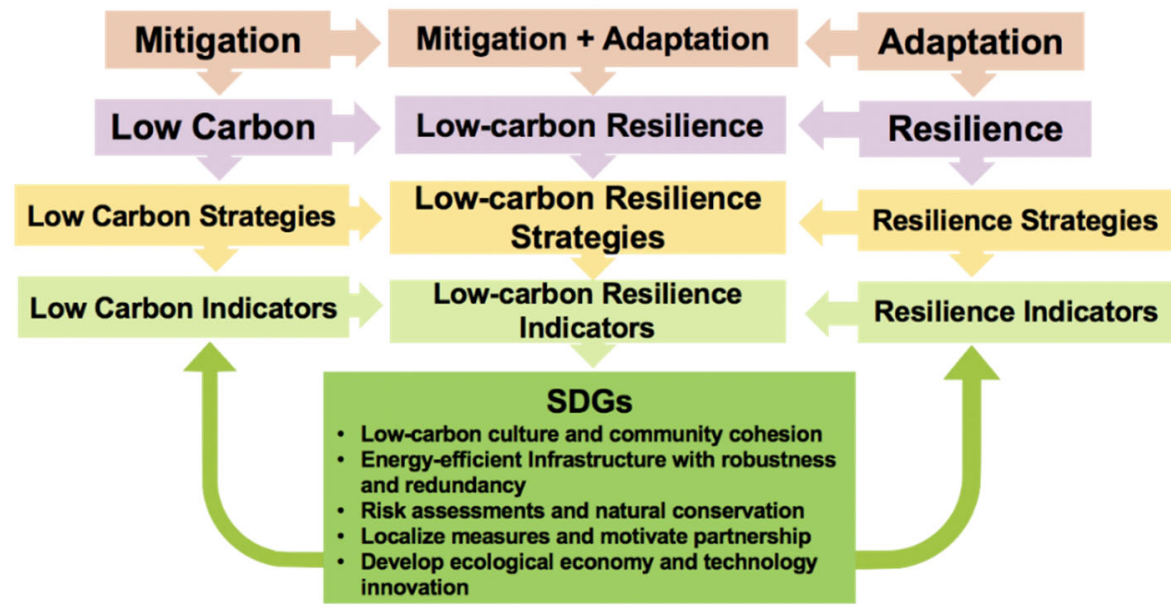

Fig. 4. Low-carbon resilience strategies \& KPIs development framework.

Table 1. The analysis of LCR strategies.

\begin{tabular}{|c|c|c|c|c|}
\hline $\begin{array}{l}\text { Low-carbon } \\
\text { Resilience Issues }\end{array}$ & $\begin{array}{l}\text { Low-carbon Strategic } \\
\text { Keywords }\end{array}$ & $\begin{array}{l}\text { Resilience Strategic } \\
\text { Keywords }\end{array}$ & $\begin{array}{l}\text { Low-carbon Resilience } \\
\text { Strategic Enhancements }\end{array}$ & SDGs \\
\hline Society & Low-carbon Engagement & $\begin{array}{l}\text { Inclusion } \\
\text { Cohesion } \\
\text { Diversity }\end{array}$ & $\begin{array}{l}\text { 1.Public Education; } \\
\text { 2. Communication } \\
\text { 3. Public Participation }\end{array}$ & $\begin{array}{l}\text { SDGs: } 3,10 \text {, } \\
11,16\end{array}$ \\
\hline Infrastructure & $\begin{array}{l}\text { Green } \\
\text { Energy-efficiency }\end{array}$ & $\begin{array}{l}\text { Robustness } \\
\text { Redundancy }\end{array}$ & $\begin{array}{l}\text { 1. Command and Control; } \\
\text { 2. Technical Assistance }\end{array}$ & SDGs: $7,9,11$ \\
\hline Environment & Sustainability Ecology & $\begin{array}{l}\text { Preparedness } \\
\text { Awareness }\end{array}$ & $\begin{array}{l}\text { 1. Command \& Control; } \\
\text { 2. Natural Conservation; } \\
\text { 3. Vulnerability and Risk } \\
\text { Assessment }\end{array}$ & $\begin{array}{l}\text { SDGs: } 11,13 \text {, } \\
14,15\end{array}$ \\
\hline Governance & Effectiveness Strongness & $\begin{array}{l}\text { Reflectiveness } \\
\text { Collaboration }\end{array}$ & $\begin{array}{l}\text { 1. Localisation; } \\
\text { 2. Collaboration and } \\
\text { Partnership }\end{array}$ & SDGs: 16,17 \\
\hline Economy & Circulation Green growth & $\begin{array}{l}\text { Sustainability } \\
\text { Digitalisation }\end{array}$ & $\begin{array}{l}\text { 1. Economic Instruments; } \\
\text { 2. Technical assistance }\end{array}$ & SDGs: $8,9,11$ \\
\hline
\end{tabular}

- Develop smart and energy-efficient infrastructure to enhance robustness and redundancy in transportation, building, electricity, water, waste and telecommunication.

- Provide technical assistance on vulnerability assessments and ecosystem building for promoting hazards awareness and preparedness.

- Strengthen effectiveness of governance and leadership by localizing measures, stakeholder partnership and international collaboration.

- Innovate in technology for developing ecological economy through economic instruments and technical assistance.

\section{Low-carbon Culture and Community Cohesion}

Low Carbon: Advocate Low-carbon Culture and Lifestyle

Culture and lifestyle play significant roles in forming energy consumption patterns, which can further influence emissions reduction and climate mitigation efficiency (Schanes et al., 2016). The importance of lifestyle and behavioral change for low carbon development has been addressed by many scholars and organizations. In the past few decades, culture has proven to make a considerable contribution to the development of a low carbon economy in European cities (Jordan, 2006). An empirical study conducted in China shows that a low carbon lifestyle has excellent effects on energy intensity reduction (Fang et al., 2012). A low carbon lifestyle is necessary for cities to achieve their emission targets because technical solutions can be disturbed by institutional bottlenecks that limit the influence on transforming cities (Moriarty and Wang, 2014). Adopting a low-carbon focused lifestyle and ingraining the practices in society is a vital sign of societal change (Skea and Nishioka, 2008). Developing low-carbon culture and lifestyles should be highly advocated. 


\section{Resilience: Create Inclusive and Cohesive Communities}

Communities play essential roles in enhancing resilience as well as in advocating a green lifestyle for sustainable development. Communities are relevant social units in cities. Citizens in a community tend to share the same cultural and social norms, but the inclusion and cohesion of communities vary across the city. Integration and cohesion are community resilience dimensions that suggest participation willingness and capability of the members (Magis, 2010). The two concepts form the community competence, demonstrating the resilience level of a city from the perspectives of wellbeing, quality of life, and the healthcare of citizens (Cutter et al., 2008; Norris et al., 2008). According to the argument of Berkes and Ross (2013), community resilience covers both social-ecological and psychological considerations. For example, creating a liveable and cohesive community requires the establishment of a healthy environment as well as interactive communication platforms that render citizens a sense of belonging. The potential benefits and improvements contributed by the community cohesion building include better public health, improved wellbeing of citizens, increased satisfaction levels, and improved environmental quality. This proves that enhancing resilience at the community level can create cobenefits in multiple sectors.

\section{Low Carbon Resilience: Advocate Low-carbon Culture in} the Process of Building Social Cohesion

Effective low-carbon resilience initiatives engage all community members in creating a better community. Advocating sustainable low-carbon cultures and promoting social cohesion are two primary emphases. Culture is a "driver" and an "enabler" of social cohesion as well as an important source of sustainable development (UNESCO, 2012). Culturally -aware strategies and projects contribute to equitable and inclusive benefits (UNESCO, 2012). Building cohesive communities can foster the development of social equality and cultural inclusion, which benefits city resilience. The formation of low-carbon culture and social cohesion operate in the context of social norms. The value and norms shared in the community further influence human behaviors, which benefits cities in a very practical manner. Public education and effective communication are the keys to culture and cohesion framing, based on which public engagement and civic participation are likely to boost (Stapp, 1969; Wei et al., 2011).

\section{Energy-efficient Infrastructure with Robustness and Redundancy \\ Low Carbon: Develop Green and Energy-efficient Infrastructure}

According to the data from the International Energy Agency (IEA), fossil-fuels take up nearly $70 \%$ of growth in global energy consumption (UNFCCC, 2019). In 2018, greenhouse gas emission rose to $1.7 \%$, which has been the highest since 2013 (IEA, 2018). Data shows that infrastructure sectors account for the majority of urban $\mathrm{CO}_{2}$ emission, especially in terms of electricity and heat, transportation, and buildings (IEA, 2018). Electricity and heat accounted for $42 \%$ of the $\mathrm{CO}_{2}$ emission around the world in 2016, which makes the combination the most excellent source of emissions (IEA, 2018). This suggests that developing carbonized electricity could significantly reduce global greenhouse gas emissions. Additionally, electricity is acknowledged to be a substitute for fossil fuels. Low-carbon electricity is expected to dominate the energy supply pattern in decades to come, which will pose challenges as well as opportunities to cities (Hertwich et al., 2015). Transportation is the second-largest source of $\mathrm{CO}_{2}$ emission, as well as one of the main contributors to the worsening air quality in cities (WHO, $2019 b$ ). With the implementation of mitigation policies, and the development of technology, the growth of transport emission has been slightly slower than the last decade (IEA, 2018). As a remarkable synergy indicated by $\mathrm{Wu}$ et al. (2020), the application of clean alternative fuels for vehicles has made less unhealthy impacts on human. In terms of the buildings sector, it contributed to $36 \%$ of final energy consumption around the world, which resulted in $39 \%$ of $\mathrm{CO}_{2}$ emissions (IEA, 2017), indicating great potential for $\mathrm{CO}_{2}$ reduction. Similar observations are also reported by Xiang et al. (2019), which show that energy-saving renovations of existing buildings can effectively eliminate greenhouse gas emission. As global carbon emission is going up dramatically, decarbonization of the infrastructure sectors is crucial for the city's low carbon strategies.

\section{Resilience: Enhance Infrastructure Robustness and Redundancy}

Robustness and redundancy are two necessary qualities of a resilience city. Robustness reflects the competence to resist disasters, and dismissal shows the availability of resources when emergencies occur (ARUP, 2014). The enhancement of robustness requires rigorous principles set by governors and followed by constructors. To a certain extent, the strengthening of robustness can be achieved by minimizing the internal vulnerability of infrastructure (Wang and Reed, 2017). Consequently, the vulnerability assessment turns to help robust design infrastructure. In addition to monitoring and designing, urban investments and green finance should assist in implementing infrastructure building strategies. Redundancy of infrastructure indicates the degree of safety, which allows inevitable shock and failure happening without suffering substantially, because of the multiple additional channels available to switch. For both robustness and redundancy, there are technical, organizational, social, and economic dimensions of the infrastructure (Tierney, 2003). The four perspectives highlight the contribution of professionalism, emergency management, wellbeing protection, and economic opportunities to infrastructure (O'Rourke, 2007).

\section{Low Carbon Resilience: Develop Energy Efficiency to Enhance Infrastructure Robustness and Redundancy}

Smart and energy-efficient infrastructure plays an important role in improving robustness and redundancy in the urban living environment. Since energy supply is a crucial player in urban infrastructure, a robust energy supply system should be developed for increasing the city's competence to sustainability. Accordingly, robust infrastructure should not entirely rely on merely one type of energy or on non-renewable 
ones (Lackner and Sachs, 2005). Resourcefulness is another quality of resilience that has a complementary relationship with robustness. Robustness reinforcement requires energy patterns that are more resourceful, sustainable, and efficient. In terms of redundancy, energy storage can correctly explain the scenario. Developing an energy storage system is a measure to reduce loss and increase energy-efficiency. At the same time, it can also be regarded as a way of strengthening redundancy (Ouyang et al., 2012). Robustness and redundancy for resilience are concepts regarding environmental vulnerability. As a mitigation approach, improving the energyefficiency of infrastructure can reduce the carbon emissions that cause considerable climate change and natural disasters. This suggests a potential decrease in environmental vulnerability and fewer threats for humankind.

\section{Risk Assessments and Natural Conservation}

Low Carbon: Transform into Sustainable and Ecological Land Use

Land use reform provides great opportunities for low carbon planning in cities. In the past 150 years, land use and land coverage change have caused $33 \%$ of total carbon emissions (Houghton et al., 2012). The crucial components of the natural carbon cycle, such as soil, water, and forest, can be hugely influenced by land-use policy. Soil affects the natural carbon cycle through releasing nutrients that plants need, promoting ecosystem health, and combating harmful substances (Guo and Gifford, 2002). Watersheds play a role in the carbon cycle by bridging linkages between land and marine areas (Campbell et al., 2012). Forests have a carbonabsorbing function for reducing greenhouse gas emissions through biomass and soils. Critical land-use strategies can help to mitigate climate change by mostly storing carbon in those carbon cycle components with relatively low costs (Campbell et al., 2012).

\section{Resilience: Promote Disaster Awareness and Preparedness}

While climate change causes unpredictable shocks to the environment, the promotion of disaster awareness and preparedness can significantly prevent specific harm. Since resilience is defined as the capability to "deal with change and continue to develop", consciousness and willingness will assist in predicting change and making contingency plans more critically (Moberg and Simonsen, 2011). To enhance resiliency of the city, the promotion of disaster awareness and preparedness should consider the perspectives of both governments and citizens. For governments, there should be a systematic disaster management mechanism, covering "prevention, preparedness, response and recovery" (Queensland Government, 2018). Command, control, and technical assistance are crucial for the government to manage disasters. As for the individual, the conception of awareness and preparedness should be fostered, which, is embedded with similar rationales of the aforementioned low-carbon culture framing. In addition to public education and communication, skills training turns out to be more critical in fostering disaster preparedness of local citizens (Kapucu, 2008).

\section{Low-carbon Resilience: Sustainable Land Use for} Promoting Natural Disaster Preparedness

Human activities lead to the diminishment and degradation of ecosystems. Reforming land use is essential for human beings to make up for the loss of natural assets and to alter the degrading environmental quality. The state of ecological conservation in the city reflects the extent to which the government and urban planners are aware of fundamental issues. Increasing citizen awareness can benefit sustainable land use policy by engaging the public in planting programs and motivating ecosystem protection on the individual level. The implementation of this strategy requires the efforts of public education and training, infrastructure designing and building, and effective governing and leadership. The lowcarbon resilience strategy predicts co-benefits to society and the environment which the approach has the potential to achieve.

\section{Localize Measures and Motivate Partnership Low Carbon: Strengthen Effective Governance and Leadership}

Strengthening governance and leadership affects all dimensions of both low carbon and resilience development. Compared with adaptation measures, low carbon transition for the city requires stronger command and control since the targets bound by the low carbon policy tend to have clear and specific ban on emissions. Laws and regulation should be strengthened and strict codes and standards for industries should be set up and executed (Wang et al., 2012). However, governments tend to have limited control and weak enforcement when implementing mitigation actions (Betsill and Bulkeley, 2007; Khan, 2012). This indicates the need of other instruments and approaches other than policies to assist effective governance and leadership. Economic incentives can also contribute to positive outcomes by encouraging low carbon production and consumption patterns. Public education, as mentioned in the first strategy on the social dimension, helps to frame low carbon culture and lifestyle. Beyond that, network governance that combines both regional and national governing efforts is a recommended approach to do critical decision-making for mitigation measures (Markantoni, 2016).

\section{Resilience: Develop Reflective and Collaborative \\ Governance}

It is acknowledged that adaptive governance will contribute to resilience development, especially to natural catastrophes (Djalante et al., 2011; Garmestani and Benson, 2013). The essence of adaptive governance is the multi-levels collaboration of governments and individuals (Folke et al., 2005). Another alike concept is network governance, meaning the decentralisation of the governments and empowerment of multiple stakeholders to participate in the decisionmaking process (Djalante et al., 2011). This governance approach has also been proved to be useful for overcoming multi-level barriers of climate governance (Khan, 2012). The two governance patterns have a common ground on developing collaboration among different stakeholders. Besides, reflectiveness is another key characteristic of effective adaptive and network governance, which can be 
supported by networking and cooperation. Reflective governance indicates the learning and responding capability of the government, based on which the emergencies could be better controlled and managed (Lebel et al., 2006). Therefore, applying reflectiveness and networking of governance are recommended vehicles to enhance city resilience.

\section{Low-carbon Resilience: Measures Localization and Multi-} level Collaboration

Developing reflective and collaborative governance can be regarded as a pathway to strengthen governing effectiveness and efficiency. As what is explained in both LC strategy and $\mathrm{R}$ strategy, the collaboration among different stakeholders can foster low carbon development as well as resilience improvements. Measure localization authorizes local governors the right to adjust the measures designated by senior government, depending on the uniqueness and particularity of the city. Besides, localization suggests social inclusiveness following its feature of respecting diverse cultures and consideration for regional uniqueness across the city.

\section{Develop Ecological Economy and Technology Innovation Low Carbon: Innovate in Circular and Green Economy}

The circular economy outlines the pathways to a low carbon city. It is an economic model that change the function of resources, which suggests the output to be transformed into the productive input (Preston, 2012). "Renew", "reuse", "recycle" and "repair" are the keywords to guide the way to deal with the waste or output in the circular economy (Preston, 2012). Business are encouraged and motivated to develop cleaner production systems and healthy materials with lower emission intensity. It shares the same value of sustainable economy, tackling the global challenges of resource depletion and climate change (Tukker, 2015). Additionally, green economy should be advocated for sustainable development that has more social and peoplecentred targets, including social equity and human wellbeing (Crafi et al., 2012). These two economic models provide solutions to mitigate climate change and pollution issues without hurting economic growth and business prosperity, which is also a way to enhance competitiveness for cities.

Resilience: Develop Sustainable and Ecological Economy Model

A healthy ecosystem has resilience capability inherently (Holling, 1973). It is acknowledged that the traditional economic model depends on natural assets aggressively, which is baneful to the health of ecosystem and weakens its resilience capability. Studies prove that human activities have surpassed the biosphere's capacity since the 1980s (Wackernagel et al., 2002). This derives the idea of ecological economy that aims to the harvest natural resources with economic growth by appropriately controlling labour, capital and natural assets (Brown and Roughgarden, 1995). In ecological economy, the growth pattern focuses on creating co-benefits on both economy and ecology (Brown and Roughgarden, 1995). The ecological economy model requires the redefinition of "economic progress" by adding social and ecological indicators to the performance evaluation system (Costanza, 2006). This also indicates the necessity of economic instruments to guide ecological business model transition.

\section{Low-carbon Resilience: Develop Ecological Economy and Technology Innovation}

The aforementioned economic models and concepts share the same values of environmental conservation. Integrating the economic models and concepts to formulate low carbon resilience strategies thus keeps the principle of natural protection and ecological development to generate low carbon and resilience benefits. Green finance and green accounting are significant techniques that can support decisionmakers in formulating critical roadmaps to practice the ecological economy approach. Meanwhile, the development of a circular economy will work better with the assistance of technology. Innovative technology will be a key contributor to lead the circular economy with a higher efficiency in the sectors of energy, buildings, transportation, water, telecommunication, waste, and so on, which will be discussed more specifically in the section of case studies. Combining the requirements of a circular economy and an ecological economy, the lowcarbon resilience strategy demonstrates the importance of green finance and innovative technology in a thriving and healthy economic development.

\section{Low Carbon Resilience Indicators}

According to the development framework presented earlier in the section, the indicators are designed to be in accordance with the low-carbon resilience strategies as well as to integrate low-carbon indicators and resilience indicators. With the purpose of matching indicators with strategies, the low-carbon resilience indicators are categorized into the five sectors, specifically, society, infrastructure, environment, governance and economy, which is shown in Table 2. These five sectors together form a "SIEGE" framework, based upon low-carbon resilience indicators which can reflect the strategies and tend to be goal oriented.

In order to integrate low- carbon indicators and resilience indicators to form the SIEGE framework, the study in this subsection includes: (1) collecting low-carbon indicator systems and R-indicator systems that are used by governments or are from authoritative documents; (2) learning the most commonly used indicators and allocating them into the "SIEGE" framework and; (3) analyzing and discussing the results.

\section{Performance Indicator Collection}

For collecting low-carbon indicators and resilience indicators, we reviewed 12 low-carbon evaluation systems and 6 resilience evaluation systems from authoritative intergovernmental organizations (IGOs), non-governmental organizations (NGOs) and academic journals. It shows that some indicator systems have unclear definitions and attributes, which will obfuscate viewers and increase the difficulties of allocating them. Therefore, the collection process must reflect the following principle.

First, the evaluation systems should mention "low carbon" and "resilience" in their titles, which is regarded as the high 


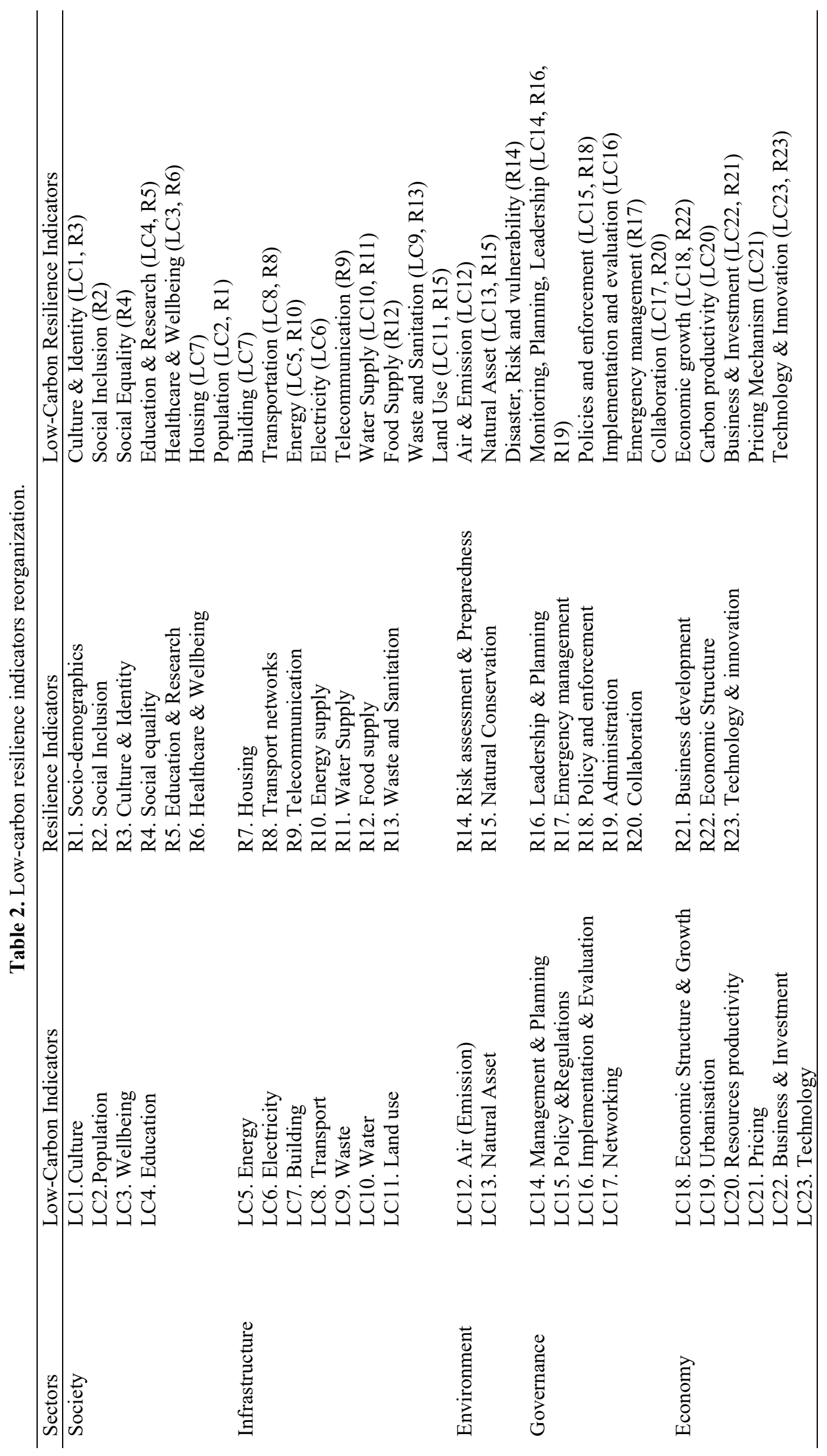


relevance to low-carbon resilience. Second, there should be clear definitions and measurements stated in the indicator systems, ensuring the specificity and measurability of each indicator. Third, the operations or frameworks should have high transferability across cities so that the results will be representative universally. The results of low-carbon indicators and resilience indicators are shown in Appendix E and Appendix F.

\section{Performance Indicators Analysis}

In the reviewed sources, the same indicators can be placed into different categories by different organizations. Since the approach adopted in this section requires a fixed redefinition and reconstruction of indicators, the interpretation of the original indicator categories in sources and the explanation of adjustment is essential for the rationality of reclassification.

\section{“SMART” Criteria}

The reorganization and redefinition of the indicators will follow the "SMART" criteria, which consist of "Specific", "Measurable", "Affordable", "Result-oriented", and "Transferable". First, the indicator should be specific, namely the definition should be clearly described with an emphasis on clarity.

Second, the indicators need to be measurable elements, without which the performance could not be critically evaluated. Third, the implementers should be able to afford to achieve what the indicators describe. A critical selfassessment is important for avoiding choosing indicators beyond reach. Fourth, the indicators should be strongly associated with the strategies and goals. Fifth, transferability is vital for a good set of indicators, which means that the index should maintain validity across time and regions.

\section{Categorical Differences}

As for low-carbon indicator systems, two types of categorization are found. One is classified by carbon emission sectors and the other is from the perspective of energy supply and demand. According to APEC's explanation, the supply and demand perspective tends to focus on the sectors that directly relate to energy consumption and carbon emissions. The sectoral view includes other fields that indirectly influence low carbon development, including social, governing and economic considerations. Applying the sectoral classification is more comprehensive and fits into the "SIEGE" framework.

With the influence of 100 Resilient Cities, most of the resilience indicators from governments are based on the City Resilience Index (CRI) provided by the Rockefeller Foundation (ARUP, 2014). The CRI sets four categories, which are "health and wellbeing", "infrastructure and ecosystems", "leadership and strategy" and "economy and society". In order to classify them into "SIEGE", the original categories are redefined. As a result, "health", "wellbeing," and "society" are identified as social aspects; "ecosystems" belong to the environment; "leadership and strategy" are categorized in governance. Accordingly, the CRI framework is reorganized to match the "SIEGE". With the consistency of indicator categories, the efficiency of integrating multiple sets of data is enhanced.

\section{$\underline{\text { Co-existence }}$}

Co-existence is another complex problem for classification. Taking the low-carbon indicator systems as examples, in the supply and demand view, energy consumption refers to the demand side, including the concerns on infrastructure such as transportation, building and waste. Carbon emissions are derived from the supply side, which is energy-centered as well as environmentally related. As a result, the indicators based on the energy supply and demand logic will cover infrastructure and environmental categories. This indicates the need to be context-specific to ensure the accuracy of the classification and redefinition.

In the case of more specific indicators such as resource productivity and economic growth, an important rule is to refer to the metrics and measures of the indicators and sort their emphases. For instance, although natural resources are key variables of the parameters of resource productivity, the focus and purport of this indicator are to discern the economic efficiency. The result, as a subdivision of fertility, is defined with economic indicators. In addition to the measures, the attributes of the indicators are also relevant to the interpretation and classification. Urbanization is an example that the rate is calculated by the size of the population, which seems to belong to the social category. However, its attributes and connotation include more economic implications such as the increased portion of the secondary and tertiary industries and the decrease in the agricultural sector. As a result, urbanization is regarded as an economic indicator because more weight in attributes allow the analysis to get closer to the essence of the indicator.

\section{SOCIAL PERSPECTIVE}

Low-carbon resilience is an all-around concept which includes a wide variety of topics, from technology and management to societal aspects. Every perspective is vital towards implementing low-carbon resilience plans in a city and thus, this section discusses low-carbon resilience implementation plans in a social perspective in detail based on strategies as well as key performance indicators which were introduced in the previous section.

\section{Society and LCR Approach}

The society and low-carbon resilience notions are closely interrelated. Ambient air quality degradation is affected by collective human behaviors (e.g., transport and the operation of coal power plant) while human health is impacted by the sources in the environment (Masiol et al., 2019; Wei et al., 2019). In order to implement a low-carbon resilience plan in a city comprehensively, one of the first steps is to understand its relationship with the society we human beings live in. In this subsection, sustainability, the goal of implementing low-carbon resilience plans, will be first examined from the sociological perspective. Then, the principle of achieving low-carbon resilience in the social division will be further introduced. 


\section{Sociological Notion of Sustainability}

Sustainability relates to the concept of changing attitude and behavior. With this fundamental concern, exploring groups of people and communities is of necessity in sustainable discussions (Karami and Keshavarz, 2010). The social aspect of sustainability addresses daily activities such as basic human needs, equity, life quality, and employment (Altieri, 1992). However, societal sustainability is not intact without embracing the impact of human exploitation on nature (Redclift and Woodgate, 2013). Integrating discussions of human and natural activities as well as prospects in different contexts, sociological perception of sustainability is presented (Karami et al., 2010).

\section{Implementing LCR Approach in Social Division}

Low-carbon Resilience is a promising topic worldwide; implementing a low-carbon resilience approach in society is, therefore, an important practice. Low-carbon resilient cities benefit society in various aspects, from the environment, and infrastructure to human beings. It is relevant to everyday life, and hence, probing the topic from a social perspective is useful. To be able to execute the low-carbon resilience thinking and action, communication to public is a necessary task. Collaborating with various stakeholders, government agencies and countries at different levels is necessary to execute low-carbon resilience approach (Harford and Raftis, 2018). To further examine the societal influence of low-carbon resilience approach implementation, it is justifiable to collaborate with different populations, especially the oftenoverlooked socio-economically weak communities (Jabareen, 2013).

\section{"5P Scheme" to Enhance Society Low-Carbon Resilience}

Targeting on realizing low-carbon resilience in cities practically, a "5P scheme" to enhance society low-carbon resilience is introduced in this subsection, with the 5Ps representing public education, public awareness, public participation, public support, and public partnership, respectively (Fig. 5). Pragmatic approaches categorized under each component of the $5 \mathrm{P}$ are presented, aiming to achieve city sustainability and implementing society lowcarbon resilience actions.

\section{Public Education}

To reach the sustainable development goals proposed by the United Nations as well as helping the community become more resilient to climate impacts, improving environmental education of various populations is necessary. Therefore, three targeted populations including students, vulnerable people, and the general public are introduced as follows.

\section{Approach 1: Environmental Curriculum in School}

An increasing number of climate disasters occurred in the past decade, and it was found that land degradation as well

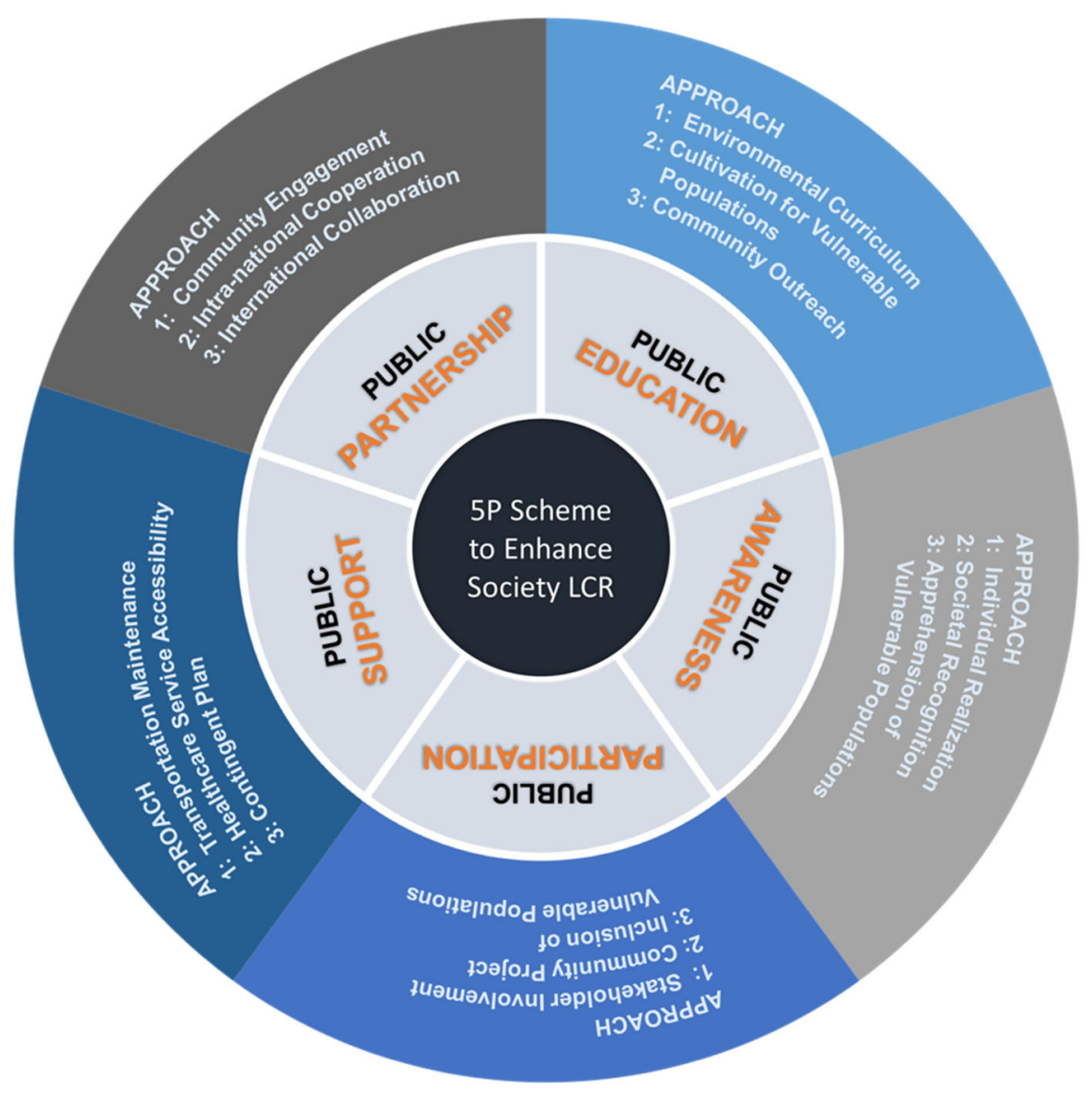

Fig. 5. "5P Scheme" to enhance society LCR. 
as greenhouse gas emissions are two significant factors contributing to climate change (Scholes et al., 2018). However, school education does not put much emphasis on this concerned issue. Hence, it is suggested to include courses introducing the cost and consequence of natural resources depletion, sustainable development, climate impact, and so on (UNISDR, 2012). On top of this, introducing free experimental courses is advantageous. With personal experience of environmental problems, students will have a better understanding of the importance of low-carbon resilient cities.

\section{Approach 2: Cultivation for Vulnerable Populations}

Socio-economically weak populations are more vulnerable to the negative impacts of climate incidents. This group of people includes those with low income, low education level, barriers in language, and those who are deprived owing to one's gender and age (Jabareen, 2013). These vulnerable populations have limited understanding of how to respond to emergent environmental events and often, are the ones most influenced by environmental disasters (Walker and Burningham, 2011). Educating vulnerable populations reduces the knowledge gap regarding environmental adaptation between groups of people and helps cultivate vulnerable groups in responding to climate disasters. By reducing societal inequalities, the city will become more resilient (Jabareen, 2013).

\section{Approach 3: Community Outreach}

Aside from student and vulnerable populations, disseminating and educating the public with concepts regarding low-carbon resilience is of importance. Academic professionals are encouraged to go public with their knowledge and guide the government as well as the community in managing the environmental impacts (UNISDR, 2012). Conducting lowcarbon, sustainable training programs for local volunteers also helps intensify the resiliency of society.

\section{Public Awareness}

Lacking awareness of socio-environmental issues is a major problem in society and hinders the sensitivity of people to the environmental impact. To enhance resilience and reduce vulnerability to climate change impacts, cities need to develop a greater awareness of low-carbon resilience implementation (Adger, 2001). Three approaches are then introduced to raise public awareness of such issues.

\section{Approach 1: Individual Realization}

On the individual level, schools, corporations, and organizations are encouraged to integrate low-carbon resilience activities in the daily tasks. That is, asking students to do a carbon-reducing job per day while they are at home. For instance, turning off lights and decreasing the water usage. In corporations and organizations, setting up areas for green plantings not only enhances the well-being of individuals but helps lesson carbon emission impacts. Googleplex, the head quarter of Google shows that employees are more aware of environment resilience through practicing "nature engineer" activities (Miller, 2015). Through individualistic involvement of carbon-reducing tasks, individuals will be more alert to city resilience.

\section{Approach 2: Society Recognition}

To raise the public awareness of environmental issues and to promote the low-carbon resilience measurements, one direction is to integrate low-carbon resistant concepts into daily activities. Governments should organize public hearings discussing low-carbon resilience and ways to reduce disaster impacts on important gatherings; for instance, the anniversary of past disasters (UNISDR, 2012). In addition to scrutinizing the low-carbon resilience approaches on certain occasions, integrating low-carbon resilience discussions in daily settings is of benefit. Encourage media and news authorities to include low-carbon resilience reporting helps enhance community awareness of climate change impact as well as notions of low-carbon resilience.

\section{Approach 3: Apprehension of Vulnerable Populations}

Vulnerable populations have relatively low awareness toward resilience concepts owing to lower levels of education and lacking accessibility to environmental knowledge (Evans et al., 2002; Özden, 2008). Adopting diversified methods to promote low-carbon resilience awareness campaigns helps understanding and resolving localize environmental issues. For instance, encouraging vulnerable populations to engage in low-carbon resilience measures through reinforcement mechanism and propagating low-carbon resilience campaigns through visuals as well as animations to involve illiteracies are two examples. The awareness gap and inequity in the community can be reduced by raising low-carbon resilience awareness of various populations.

\section{Public Participation}

Public participation in decision-making is vital in shaping city resilience (Jabareen, 2013). Weaker governance city cannot engage its residents in the planning process and typically fails to meet the obstacles of resilience. A more resilient city, on the other hand, values an inclusive decisionmaking process and promotes collaboration between government and people (Gupta and Vegelin, 2016). Aiming at escalating public participation in low-carbon resilience planning as well as operation, three approaches are presented as follows.

\section{Approach 1: Stakeholder Involvement}

Involving multi-stakeholders in the process of low-carbon resilience policymaking reduces inequity in the community and can better represent different populations. Authorities are encouraged to organize open platforms to discuss climate change issues with local societies as well as relevant associations (UNISDR, 2012). Local governments should also encourage stakeholders from various backgrounds, especially the vulnerable groups, to actively involve with the low-carbon resilience measures.

\section{Approach 2: Community Project}

Community engagement magnifies efficiency by establishing a low-carbon resilient city. Through 
implementing various low-carbon resilience measures along with in-depth discussions of low-carbon resilience topics, the community can benefit in multiple aspects. Building green roofs in the community are one example. As suggested by Xiang et al. (2019), energy-saving renovation of buildings can effectively reduce the $\mathrm{CO}_{2}$ emissions associated with the constructions. Consequently, building the green roofs is relevant to achieving low-carbon resilient goals and the space-efficient recreation areas can also be created. Additionally, healthcare costs are likely to be reduced due to decreasing temperatures, reducing the amount of $\mathrm{CO}_{2}$ and increasing nature diversity in the area (Harford and Raftis, 2018). Another profitable community project is to construct low-carbon disaster-resilient housing. Integrating energy efficient technologies, low-carbon materials and resilient design, users can enjoy various merits and contribute to community low-carbon resilience (Charoenkit and Kumar, 2017).

\section{Approach 3: Inclusion of Vulnerable Populations}

Maciejczyk et al. (2018) reported that air pollution significantly impacts the cardiovascular responses in animals. For instance, the hazardous components in air induced by carbon emission affected the health of humans, especially the vulnerable populations. However, a limited number of lowcarbon resilience plans representing vulnerable populations increases the liability of urban residents (UNISDR, 2012). To minimize the impact of low representativeness of vulnerable groups in low-carbon resilience policies, the government should invest in pro-vulnerable innovations. One way is to open-up channels for the vulnerable groups to express and discuss with local authorities the low-carbon resilience approaches (Redclift, 2014). Through an increasing engagement of assailable populations in the policy-making process, their livelihood, social ties, and resilience to climate change will be strengthened.

\section{Public Support}

A stable transportation system, accessibility to healthcare service, and a well-planned contingency system are elements of a sustainable-resilient city (Clercq and Bertolini, 2003; Saviano et al., 2018). Solid constructions and sufficient healthcare services after a climate event demonstrate adequate support from the government and the community. Therefore, three approaches are proposed to strengthen public support regarding low-carbon resilience implementations.

\section{Approach 1: Transportation Maintenance}

The transportation system connects different parts of the city and bonds people in the community. It is of extreme importance to maintain transportation system performance in all climate conditions. Maintaining and enhancing public transportation accessibility after a climate event demonstrates public support in the community and thus, contributes to community resilience (Jeon et al., 2010). Further, people living in metropolitans spend a great amount of time in transit traffic each day. The longer times spend in transit traffic contribute to a higher risk of increased exposure to pollutants (Kecorius et al., 2018). To reduce the adverse health effect of city residents as well as to increases city lowcarbon resilience, implementing green transportation is necessary. Constructing a bike rental system, promoting use of electric scooters, and encouraging utilization of public shipments are the representative of community low-carbon resilience.

\section{Approach 2: Healthcare Service Accessibility}

To enhance the resiliency of society, guaranteed accessibility to healthcare services are needed. Providing post-event trauma care and injury service facilitates the recovery from climate events, which then leads to better resilience of the community. Additionally, integrating healthcare assistance with disaster emergency services is seemly and intensifies society resilience (UNISDR, 2012).

\section{Approach 3: Contingent Plan}

Establishing a well-prepared contingency plan for climate events enhances the resilience of a community. Through comprehensive consequence estimation and developing an adaptive strategy of projected climate impacts, people will be prepared and can better address potential hazards (Harford and Raftis, 2018). The contingency plan should include coping mechanisms in various aspects, to name a few, a means for keeping city infrastructures working after a major event, strategies to meet post-event healthcare needs, and directives to rebuild destroyed facilities. Forming a well-organized contingency plan for future climate events leads to a positive view of society in the future which further contributes to the well-being of a community. With preparedness for climate events, people are likely to feel supported by society and will acquire an improved adjustment ability.

\section{Public Partnership}

The collaboration of government, local populations, and stakeholders of different levels practicing low-carbon resilience approaches benefits community sustainability. Establishing a firm partnership inwardly in the society and outwardly in a global context is essential to achieving climate change goals (Jabareen, 2013). To build stronger public relationships, three approaches are discussed.

\section{Approach 1: Community Engagement}

Community engagement can be considered in multiple aspects. From the view of local government, it is vital to formulate plans ensuring the participation of residents in drafting a low-carbon resilience approach plan (UNISDR, 2012). Through the process of low-carbon resilience policymaking along with encouragement in environmental issues assistance, people are likely to be sensitive to the long-term development of the city. At the same time, pro-environment organizations are recommended to sign up for campaigns advocating public engagement in low-carbon resilience policy development (UNISDR, 2012). With the involvement of different sectors, resilience plans can be better realized in practice.

\section{Approach 2: Intra-national Cooperation}

Within a nation, cooperation between private sectors, 
different levels of government and organizations improve the efficiency of low-carbon resilience plan implementation. Building partnerships in environmental projects with relevant stakeholders is clearly needed (UNISDR, 2012). Beyond this, academic professionals should coordinate with the regional governments in applying research on climate impact reduction as well as risk evaluation (UNISDR, 2012). With close connections between local authorities, people, and academia, low-carbon resilience strategies can be better fulfilled.

\section{Approach 3: International Collaboration}

In addition to intra-national cooperation, learning from other countries promotes low-carbon resilient city development. International support and collaboration in low-carbon resilience projects broaden the effect to a broader context. Alternative strategies for climate impact may also be created through sharing and exchanging experiences with other actors (UNISDR, 2012). Additionally, international contact is unavoidable in the highly globalized world today. Environmental hazards and pollutions are likely to disperse through regional transport (Wen et al., 2018). Hence, partnering with multi-parties is essential and beneficial to development of international collaboration program for lowcarbon resilience city towards SDGs.

\section{CHALLENGES AND PERSPECTIVES}

To implement a low-carbon resilience approach in cities towards sustainable development goals, governments should achieve a holistic executive mechanism, covering social, infrastructure, environment, governance and economics. Through the critical SIEGE planning, 5P enhancement, and innovation technology coordination, the low-carbon resilience approach can contribute to the sustainable development of cities. However, there are also challenges for implementation that governors should notice, which stem from the perspectives of institution, regulation, finance, techniques and communication.

\section{Institution}

When governments execute low-carbon resilience measures, there is a great potential for institutional barriers that can hinder the efficiency and effectiveness of their efforts. Lowcarbon resilience is a multi-disciplinary concept that the implementation of relates to multiple sectors as well as to different institutions. This can accentuate the institutional barriers and result in governing challenges. Rights and obligations for different departments can be vague, unclear or overlapping, which further increases the difficulties of defining the accountability of specific problems. For some underdeveloped cities, the lack of mechanism and a platform for resource integration is a common problem. This indicates the need for building a LCR-centered organization that focuses on the coordination of relevant resources and stakeholders to maximize the positive impact of multi-sectoral efforts.

\section{Regulation}

Regulatory bottlenecks are challenges that usually confront city planners and governors. Similar to institutional barriers, the most difficult part is derived from the complexity of low-carbon resilience dimensions. Moreover, for most governments, low-carbon resilience is an emerging innovative approach that requires high integration and coordination capability. Current policies and guidance for climate and environmental issues tend to separate mitigation and adaptation. There are inadequate consistencies and lack of convergence of policy guidance for mitigation and adaptation. A sound performance evaluation system for lowcarbon resilience is absent in most cities, which negatively influences the efficiency and rationality of low-carbon resilience implementation.

\section{Finance}

The development of low-carbon resilience depends considerably on financing during the decision-making process. Green finance could be the top priority, however it comes with multiple difficulties at regional, national and international levels. At different levels, the debate about the preferences and obstacles can diverge. Trade-offs should be made to maximize benefits. Budgeting can be a problem for infrastructure building and technology innovation. There are potential challenges for short term investments and budgeting problems. For private sectors, lack of financial knowledge can hinder the green business investment due to the ignorance of financial options.

\section{Techniques}

The need for integration and coordination capability suggests the technical demand for low-carbon resilience implementation. Lack of leaders and professionals with the specialized expertise can be a significant challenge since human capital is the essence of governance. Cultivation and education are needed for enriching the leadership team specially designed for low-carbon resilience. In regard to the importance of innovative technology, technical problems may occur due to the uncertainty of transferability and effectiveness. Rigorous research and empirical studies are pivotal in dealing with these technical challenges.

\section{Communication}

Several challenges are likely to occur during the process of communication. For peripheral regions, citizens may not have access to sufficient education and information. In other cases, the social value of individual communities may have conflicts with low-carbon resilience, which makes the lowcarbon resilience concept unacceptable. Negotiation and mediation are another communication agenda that is difficult to organize. For different groups of stakeholders, divergent interests usually bring groups into conflict, which means a negotiating mechanism is needed to solve or mitigate the conflicts.

In general, multiple barriers and bottlenecks will need to be overcome during the process of low-carbon resilience implementation. Governments should consider institutional, regulatory, financial, technical and communication issues holistically, planning contingency actions for unexpected outcomes. Beyond that, the study on low-carbon resilience 
can be further developed through the analysis of synergies and trade-offs between low carbon and resilience measures. Effective pathways to integrated implementation will require empirical data and more in-depth research.

\section{CONCLUSIONS AND PROSPECTS}

Humanity is facing a rising number of global challenges in recent decades, such as natural resource depletion, environmental quality deterioration and climate change. It is of necessary for humans to take immediate action to alleviate these issues. Aiming to live harmoniously with nature, the United Nations adopted the lead role and proposed 17 sustainable development goals. The concepts of low carbon and resilience are among those carefully examined in this study, integrating both mitigation and adaptation notions with the understandings of past low-carbon resilience movements, the strategic framework of low-carbon resilience is presented. Low carbon resilience is an urban planning and governing concept that aims at achieving sustainable development goals. Based on the overview of urban planning concepts towards sustainable development, the evolution of the low-carbon resilient cities is presented. Evaluation from this study suggests that low carbon cities share a similar economic, environmental and social value with the healthy city, the resilient city, the eco-city, the sustainable city, the green city and the low carbon city. Regarding these core values of lowcarbon resilience, a theoretical framework is developed to guide the strategic planning for mitigation and adaptation, on which the "SIEGE" scheme is generated. The strategies and indicators regarding society, infrastructure, environment, governance and economy are discussed. Additionally, public education, public awareness, public participation, public support and public partnership collectively formulate a " $5 \mathrm{P}$ " scheme for supporting the implementation plan from the social perspective. Finally, the discussion about challenges and perspectives demonstrates the multiple potential barriers that might confront cities; thus, comprehensive contingency plans of low-carbon resilience require considerations of multi-faceted issues. Further and more profound research on low-carbon resilience is crucial for overcoming those barriers as well as contributing to the effective and efficient urban governance towards sustainable development goals.

\section{ACKNOWLEDGEMENTS}

High appreciation goes to the Ministry of Science and Technology (MOST) of Taiwan under Grant Number MOST 107-2221-E-002-009-MY3 and MOST 108-2911-I002-562 for the financial support.

\section{SUPPLEMENTARY MATERIAL}

Supplementary data associated with this article can be found in the online version at http://www.aaqr.org.

\section{REFERENCES}

Adger, W.N. (2001). Scales of governance and environmental justice for adaptation and mitigation of climate change. $J$. Int. Dev. 13: 921-931.

Altieri, M.A. (1992). Sustainable agricultural development in Latin America: Exploring the possibilities. Agric. Ecosyst. Environ. 39: 1-21.

Arrhenius, S. (1896). XXXI. On the influence of carbonic acid in the air upon the temperature of the ground. London, Edinburgh Dublin Philos. Mag. J. Sci. 41: 237276. doi: 10.1080/14786449608620846.

ARUP (2014). City resilience framework: City resilience index. The Rockefeller Foundation and ARUP. https://www.urban-response.org/system/files/content/res ource/files/main/city-resilience-framework-ARUP-april2014.pdf.

Awofeso, N. (2003). The Healthy Cities approach: Reflections on a framework for improving global health. Bull. World Health Organ. 81: 222-223.

Beatley, T. (2000). Green urbanism: Lessons from European cities. Island Press, Washington DC, pp. 3-26.

Beigi, S. (2015). The timeline of resilience: A roadmap for cross operationalization of resilience. Ecol. Soc. 18.

Berkes, F. and Ross, H. (2013). Community resilience: Toward an integrated approach. Soc. Nat. Resour. 26: 520.

Betsill, M. and Bulkeley, H. (2007). Looking back and thinking ahead: A decade of cities and climate change research. Local Environ. 12: 447-456.

BP (2016). BP statistical review of world energy June 2016. OilProduction website, http://oilproduction.net/files/espe cial-BP/bp-statistical-review-of-world-energy-2016-fullreport.pdf, Last Access: 15 August 152019.

Brown, G. and Roughgarden, J. (1995). An ecological economy: Notes on harvest and growth. In Biodiversity loss: Economic and ecological issues, Perrings, C., Maler, K.G., Folke, C., Holling, C.S. and Jansson, B.O. (Eds.), Cambridge University Press, Cambridge, pp. 150-189.

Brundtland, G.H. (1987). Brundtland report. Our common future. Comissão Mundial.

Campbell, C.D., Lilly, A., Towers, W., Chapman, S.J., Werritty, A. and Hanley, N. (2012). Land use and a lowcarbon society. Earth Environ. Sci. Trans. R. Soc. Edinburgh 103: 165-173.

Carfi, D. and Schilirò, D. (2012). A coopetitive model for the green economy. Econ. Modell. 29: 1215-1219.

Centre for Research on the Epidemiology of Disasters (CRED) (2019). Natural Disaster 2018. The International Disaster Database. https://www.cred.be/sites/default/files/ CREDNaturalDisaster2018.pdf.

Chadwick, E. (1843). Report on the sanitary conditions of the labouring population of Great Britain. A supplementary report on the results of a special inquiry into the practice of interment in towns. Made at the request of Her Majesty's principal secretary of state for the Home department. W. Clowes and Sons, London.

Charoenkit, S. and Kumar, S. (2017). Building low-carbon and disaster-resilient communities: Integrating climate mitigation and adaptation into the assessment of self-help housing design. Mitigation Adapt. Strategies Global Change 22: 695-728. 
Clercq, F. and Bertolini, L. (2003). Achieving sustainable accessibility: An evaluation of policy measures in the Amsterdam area. Built Environ. 29: 36-47.

Cooper, A. and Johnson, C. (2018). Now near 100 million bpd, when will oil demand peak? https://www.reuters.com/ article/us-oil-demand-peak/now-near-100-million-bpd-w hen-will-oil-demand-peak-idUSKCN1M01TC.

Costanza, R. (2006). Nature: Ecosystems without commodifying them. Nature 443: 749-749.

Creech, H. (2012). Sustainable development timeline. International Institute of Sustainable Development, pp. 1-4.

Cutter, S.L., Barnes, L., Berry, M., Burton, C., Evans, E., Tate, E. and Webb, J. (2008). A place-based model for understanding community resilience to natural disasters. Global Environ. Change 18: 598-606.

De Jong, M., Joss, S., Schraven, D., Zhan, C. and Weijnen, M. (2015). Sustainable-smart-resilient-low carbon-ecoknowledge cities; making sense of a multitude of concepts promoting sustainable urbanization. J. Cleaner Prod. 109: 25-38.

Denchak, M. (2018). Water pollution facts, types, causes and effects of water pollution. The Natural Resources Defense Council, https://www.nrdc.org/stories/waterpollution-everything-you-need-know, Last Access: 25 August 2019.

Djalante, R., Holley, C. and Thomalla, F. (2011). Adaptive governance and managing resilience to natural hazards. Int. J. Disaster Risk Sci. 2: 1-14.

Eberlein, S. (2018). Ecocity World Summit. https://ecocitybu ilders.org/wp-content/uploads/2018/08/EWS_BidManua 12021_web.pdf.

European Landscape Contractors Association (ELCA) (2012). Green City Europe - for a better life in European cities. Green City Europe ELCA Research Workshop. http://urbanspace.rec.org/files/ELCA-Boschuere_140911. pdf.

Evans, D.T., Fullilove, M.T., Green, L. and Levison, M. (2002). Awareness of environmental risks and protective actions among minority women in Northern Manhattan. Environ. Health Perspect. 110: 271-275.

Fang, G., Tian, L., Sun, M. and Fu, M. (2012). Analysis and application of a novel three-dimensional energy-saving and emission-reduction dynamic evolution system. Energy 40: 291-299.

Fisher, S. (2013). Low-carbon resilient development in the least developed countries. International Institute for Environment and Development, UK.

Folke, C., Hahn, T., Olsson, P. and Norberg, J. (2005). Adaptive governance of social-ecological systems. Annu. Rev. Environ. Resour. 30: 441-473.

Garmestani, A.S. and Benson, M.H. (2013). A framework for resilience-based governance of social-ecological systems. Ecol. Soc. 18: 9.

Gilbert, S.W. (2010). Disaster resilience: A guide to the literature. NIST special publication, 1117. U.S. Department of Commerce National Institute of Standards and Technology, USA.

Godschalk, D.R. (2003). Urban hazard mitigation: Creating resilient cities. Nat. Hazard. Rev. 4: 136-143.
Guo, L.B. and Gifford, R.M. (2002). Soil carbon stocks and land use change: A meta analysis. Global Change Biol. 8: 345-360.

Gupta, J. and Vegelin, C. (2016). Sustainable development goals and inclusive development. Int. Environ. Agreements Politics Law Econ. 16: 433-448.

Harford, D. and Raftis, C. (2018). Low carbon resilience: Best practices for professionals. Adaptation to Climate Change Team/Simon Fraser University, Canada.

Hertwich, E.G., Gibon, T., Bouman, E.A., Arvesen, A., Suh, S., Heath, G.A., Bergesen, J.D., Ramirez, A., Vega, M.I. and Shi, L. (2015). Integrated life-cycle assessment of electricity-supply scenarios confirms global environmental benefit of low-carbon technologies. PNAS 112: 62776282. doi: 10.1073/pnas.1312753111.

Holling, C.S. (1973). Resilience and stability of ecological systems. Annu. Rev. Ecol. Syst. 4: 1-23.

Houghton, R.A., House, J.I., Pongratz, J., van der Werf, G.R., DeFries, R.S., Hansen, M.C., Le Quéré, C. and Ramankutty, N. (2012). Carbon emissions from land use and land-cover change. Biogeosciences 9: 5125-5142.

International Association of Oil \& Gas Producers (IOGP) (2017). The future of oil \& gas: Shedding light on the obvious. International Association of Oil \& Gas Producers. http://32zn56499nov99m251h4e9t8-wpengine.netdna-ssl. com/bookstore/wp-content/uploads/sites/2/2017/12/GEB -Future-of-OG-FINAL-15-Feb.pdf.

International Energy Agency (IEA) (2016). Cities are at the frontline of the energy transition. The International Energy Agency. https://www.iea.org/news/cities-are-atthe-frontline-of-the-energy-transition.

International Energy Agency (IEA) (2017). Globa Status Report 2017: Towards a zero-emission, efficient, and resilient buildings and construction sector. International Energy Agency. https://www.worldgbc.org/sites/default/ files/UNEP\%20188 GABC_en\%20\%28web\%29.pdf.

International Energy Agency (IEA) (2018). World Energy Outlook 2018. The International Energy Agency. https://www.iea.org/reports/world-energy-outlook-2018.

International Organization for Migration, Global Migration Data Analysis Centre (IOM) (2019). Environmental migration. https://migrationdataportal.org/themes/enviro nmental_migration, Last Access: 11 August 2019.

Jabareen, $\bar{Y}$. (2013). Planning the resilient city: Concepts and strategies for coping with climate change and environmental risk. Cities 31: 220-229. doi: 10.1016/j.cit ies.2012.05.004.

Jeon, C., Amekudzi, A. and Guensler, R. (2010). Evaluating plan alternatives for transportation system sustainability: Atlanta metropolitan region. Int. J. Sustainable Transp. 4: 227-247.

Jordan, A. (2006). The environmental case for Europe: Britain's European environmental policy. The Centre for Social and Economic Research on the Global Environment (CSERGE). https://www.econstor.eu/bitstre am/10419/80244/1/513782648.pdf.

Kapucu, N. (2008). Culture of preparedness: Household disaster preparedness. Disaster Prev. Manage. 17: 526535. doi: 10.1108/09653560810901773. 
Karami, E. and Keshavarz, M. (2010). Sociology of sustainable agriculture. In Sociology, organic farming, climate change and soil science, Lichtfouse, E. (Ed.), Springer Netherlands, Dordrecht, pp. 19-40.

Kecorius, S., Tamayo, E.G., Galvez, M.C., Madueño, L., Betito, G., Gonzaga-Cayetano, M., Vallar, E. and Wiedensohler, A. (2018). Activity pattern of school/ university tenants and their family members in Metro Manila - Philippines. Aerosol Air Qual. Res. 18: 2412 2419.

Lackner, K.S. and Sachs, J. (2005). A robust strategy for sustainable energy. Brookings Papers Econ. Act. 2005: 215-284.

Lannin, S. (2019). Global carbon emissions hit record high in 2018, International Energy Agency says. ABC News https://www.abc.net.au/news/2019-03-26/global-carbonemissions-hit-record-high-in-2018-according-to-iea/109 41378, Last Access: 5 August 2019.

Lawton, J.H. and Brown, V.K. (1994). Redundancy in ecosystems. In Biodiversity and ecosystem function, Schulze, E.D. and Mooney, H.A. (Eds.), Springer Berlin Heidelberg, Berlin, Heidelberg, pp. 255-270.

Leahy, S. (2018). 75\% of earth's land areas are degraded. national geographic. https://www.nationalgeographic.com/ news/2018/03/ipbes-land-degradation-environmental-da mage-report-spd/.

Lebel, L., Anderies, J.M., Campbell, B., Folke, C., HatfieldDodds, S., Hughes, T.P. and Wilson, J. (2006). Governance and the capacity to manage resilience in regional socialecological systems. Ecol. Soc. 11: 19.

Lewis, E. (2015). Green city development tool kit. Asian Development Bank Institute. https://www.think-asia.org/ hanle/11540/5151.

Lundberg, E. (2019). Facing our global environmental challenges requires efficient international cooperation. UN Environment Programme. https://www.unenvironment. org/news-and-stories/editorial/facing-our-global-environ mental-challenges-requires-efficient.

MacArthur, R.H. (1955). Fluctuations of animal populations, and a measure of community stability. Ecology 36: 553536.

Maciejczyk, P., Jin, L., Hwang, J. S., Guo, X., Zhong, M., Thurston, G., Qu, Q., Zhang, J., Sun, Q. and Chen, L.C. (2018). Association of cardiovascular responses in mice with source-apportioned $\mathrm{PM}_{2.5}$ air pollution in Beijing. Aerosol Air Qual. Res. 18: 1839-1852.

Magis, K. (2010). Community resilience: An indicator of social sustainability. Soc. Nat. Resour. 23: 401-416.

Markantoni, M. (2016). Low carbon governance: mobilizing community energy through top-down support? Environ. Policy Governance 26: 155-169.

Martín, C., McTarnaghan, S., Gilbert, D.L., Meixell, B., Rakotondrazaka, F., Diby, S., Arena, O., Gourevitch, R., Pollock, J. and López, M. (2018). Institutionalizing urban resilience: A midterm monitoring and evaluation report. 100 Resilient City. http://www.100resilientcities.org/wpcontent/uploads/2019/03/100RC-2018-Urban-InstituteMidterm-Report.pdf.

Masiol, M., Squizzato, S., Cheng, M.D., Rich, D.Q. and
Hopke, P.K. (2019). Differential probability functions for investigating long-term changes in local and regional air pollution sources. Aerosol Air Qual. Res. 19: 724-736.

Miller, K. (2015). Googleplex. Critical Sustainabilities, https://critical-sustainabilities.ucsc.edu/googleplex-moun tain-view/, Last Access: 18 August 2019.

Moberg, F. and Simonsen, S.H. (2011). What is resilience? An introduction to social-ecological research. Stockholm Resilience Centre.

Moriarty, P. and Wang, S.J. (2014). Low-carbon cities: Lifestyle changes are necessary. Energy Procedia 61: 2289-2292. doi: 10.1016/j.egypro.2014.12.439.

Müller, S.M. and Mattissek, A. (2018). Green cities: explorations and visions of urban sustainability. RCC Perspectives: Transformations in Environment and Society 2018 , no. 1 . doi: $10.5282 / \mathrm{rcc} / 8462$.

Norris, F.H., Stevens, S.P., Pfefferbaum, B., Wyche, K.F., and Pfefferbaum, R.L. (2008). Community resilience as a metaphor, theory, set of capacities, and strategy for disaster readiness. Am. J. Community Psychol. 41: 127150.

O'Rourke, T.D. (2007). Critical infrastructure, interdependencies, and resilience. The Bridge 37: 22-29.

Ouyang, M., Dueñas-Osorio, L. and Min, X. (2012). A three-stage resilience analysis framework for urban infrastructure systems. Struct. Saf. 36: 23-31.

Özden, M. (2008). Environmental awareness and attitudes of student teachers: An empirical research. Int. Res. Geog. Environ. Educ. 17: 40-55.

Pace, R., Churkina, G. and Rivera, M. (2016). How green is a green city: A review of existing indicators and approaches. Institute for Advanced Sustainability Studies. http://publications.iass-potsdam.de/pubman/item/escidoc: 1910926:4/component/escidoc:1910931/IASS_Working Paper_1910926.pdf.

Parsons, K.C. and Schuyler, D. (2004). From garden city to green city. The legacy of Ebenezer Howard. Johns Hopkins University Press, USA.

Preston, F. (2012). A Global Redesign? Shaping the Circular Economy (p. 20). Chatham House.

Queensland Government (2018). Resilient Queensland: Delivering the Queensland strategy for disaster resilience. The State of Queensland (Queensland Reconstruction Authority). https://www.qra.qld.gov.au/sites/default/files /2018-10/resilient-queensland-2018-21-summary_0.pdf.

Redclift, M. and Woodgate, G. (2013). Sociology and the environment: Discordant discourse? In Social theory and the global environment, Benton, T. and Redclift, M. (Eds.), Taylor and Francis, pp. 51-66.

Redclift, M. (2014). Sustainable development and popular participation: A framework for analysis. In Grassroots environmental action. Ghai, D. and Vivian, J.M. (Eds.), Routledge, pp. 39-65.

Richert, E.D. and Lapping, M.B. (1998). Ebenezer Howard and the garden city. J. Am. Plann. Assoc. 64: 125-127.

Ritchie, H. and Roser, M. (2017). How long before we run out of fossil fuels? Our World in Data. https://ourworldin data.org/how-long-before-we-run-out-of-fossil-fuels.

Roseland, M. (1997). Dimensions of the eco-city. Cities 14: 
197-202.

Saviano, M., Bassano, C., Piciocchi, P., Di Nauta, P. and Lettieri, M. (2018). Monitoring viability and sustainability in healthcare organizations. Sustainability 10: 3548.

Schanes, K., Giljum, S. and Hertwich, E. (2016). Low carbon lifestyles: A framework to structure consumption strategies and options to reduce carbon footprints. $J$. Cleaner Prod. 139: 1033-1043. doi: 10.1016/j.jclepro.20 16.08.154

Scholes, R., Montanarella, L., Brainich, A., Barger, N., ten Brink, B., Cantele, M., Erasmus, B., Fisher, J., Gardner, T., Holland, T.G., Kohler, F., Kotiaho, J.S., Von Maltitz, G., Nangendo, G., Pandit, R., Parrotta, J., Potts, M.D., Prince, S., Sankaran, M. and Willemen, L. (2018) Summary for policymakers of the assessment report on land degradation and restoration of the Intergovernmental Science- Policy Platform on Biodiversity and Ecosystem Services. IPBES secretariat, Bonn, Germany.

Sharifi, A. (2016). From Garden City to Eco-urbanism: The quest for sustainable neighborhood development. Sustainable Cities Soc. 20: 1-16.

Skea, J.I.M. and Nishioka, S. (2008). Policies and practices for a low-carbon society. Clim. Policy 8: 5-16. doi: 10.3763/cpol.2008.0487.

Stapp, W.B. (1969). The concept of environmental education. Environ. Educ. 1: 30-31. doi: 10.1080/001392 54.1969.10801479.

Stockholm Resilience Centre (SRC) (2019). Annual Report 2018. Stockholm Resilience Centre. https://www.stockho lmresilience.org/news--events/general-news/2019-04-09annual-report-2018.html.

The Intergovernmental Panel on Climate Change (IPCC) (2018a). Special report: Global warming of $1.5^{\circ} \mathrm{C}$. The Intergovernmental Panel on Climate Change, https://www. ipcc.ch/sr15/chapter/chapter-1/, Last Access: 5 August 2019.

The Intergovernmental Panel on Climate Change (IPCC) (2018b). Summary for policymakers of IPCC special report on global warming of $1.5^{\circ} \mathrm{C}$ approved by governmentsIPCC. https://www.ipcc.ch/2018/10/08/summary-for-pol icymakers-of-ipcc-special-report-on-global-warming-of1-5c-approved-by-governments/, Last Access: 5 August 2019.

Thomas, D. (1963). London's green belt: The evolution of an idea. Geog. J. 129: 14-24.

Tierney, K.J. (2003). Conceptualizing and measuring organizational and community resilience: Lessons from the emergency response following the September 11, 2001 attack on the World Trade Center. Disaster Research Center, University of Delaware, USA.

Tukker, A. (2015). Product services for a resource-efficient and circular economy-A review. J. Cleaner Prod. 97: 7691.

U.S. Energy Information Administration (EIA) (2015). Annual Energy Outlook 2015. Annual energy outlook 2015: With projections to 2040. Government Printing Office.

United Nations Educational, Scientific and Cultural Organization (UNESCO) (2012). Culture: A driver and an enabler of sustainable development. Thematic Think Piece. UN System Task Team on the Post-2015 UN Development Agenda.

United Nations Environment Programme (UNEP) (2011). Towards a green economy: Pathways to sustainable development and poverty eradication. United Nations. https://wedocs.unep.org/bitstream/handle/20.500.11822/ 27689/AR2018 EN.pdf? sequence=1\&isAllowed=y

United Nations Environment Programme (UNEP) (2018). Annual report 2018. United Nations. https://wedocs.unep. org/bitstream/handle/20.500.11822/27689/AR2018_EN. pdf? sequence $=1 \&$ isAllowed $=y$

United Nations Framework Convention on Climate Change (UNFCCC) (2019). Fossil fuels are biggest part of global ecological footprint. United Nations Framework Convention on Climate Change website. https://unfccc.int/news/fossil -fuels-are-biggest-part-of-global-ecological-footprint.

United Nations Office for Disaster Risk Reduction (UNISDR) (2012). Making cities resilient: My city is getting ready, 2010-2011. United Nations Office for Disaster Risk Reduction.

Urban Ecologist (2019). History: About us. Urban Ecology. http://www.urbanecology.org/history.htm

Wackernagel, M., Schulz, N.B., Deumling, D., Linares, A.C., Jenkins, M., Kapos, V., Monfreda, C., Loh, J., Myers, N., Norgaard, R. and Randers, J. (2002). Tracking the ecological overshoot of the human economy. PNAS 99: 9266-9271. doi: 10.1073/pnas.142033699.

Walker, G. and Burningham, K. (2011). Flood risk, vulnerability and environmental justice: Evidence and evaluation of inequality in a UK context. Crit. Soc. Policy 31: 216-240.

Wang, N. and Chang, Y.C. (2014). The development of policy instruments in supporting low-carbon governance in China. Renewable Sustainable Energy Rev. 35: 126135.

Wang, S. and Reed, D.A. (2017). Vulnerability and robustness of civil infrastructure systems to hurricanes. Front. Built Environ. 3: 60. doi: 10.3389/fbuil.2017.00060.

Ward, S.V. (1990). The garden city tradition re-examined. Plann. Perspect. 5: 249-256.

Wei, X., Gui, H., Liu, J., Zhang, J., Schwab, J. and Gao, M. (2019). Aerosol pollution characterization before Chinese New Year in Zhengzhou in 2014. Aerosol Air Qual. Res. 19: 1294-1306.

Wei, Z., Hulin, L. and Xuebing, A. (2011). Ecological civilization construction is the fundamental way to develop low-carbon economy. Energy Procedia 5: 839843.

Wen, W., He, X., Ma, X., Wei, P., Cheng, S., Wang, X. and Liu, L. (2018). Understanding the regional transport contributions of primary and secondary $\mathrm{PM}_{2.5}$ components over Beijing during a severe pollution episodes. Aerosol Air Qual. Res. 18: 1720-1733.

West, G.B. (2013). The challenge of resilient dynamism. World Economic Forum. https://www.weforum.org/agen da/2013/01/the-challenge-of-resilient-dynamism/, Last Access: 5 August 2019.

World Health Organization (WHO) (1998). The World 
Health Report 1998: Life in the 21st century a vision for all. http:/hist.library.paho.org/xmlui/handle/123456789/43015.

World Health Organization (WHO) (2019a). World health statistics 2019: Monitoring health for the SDGs, sustainable development goals. World Health Organization. https:/apps.who.int/iris/bitstream/handle/10665/272596/ 9789241565585-eng.pdf.

World Health Organization (WHO) (2019b). 2018 WHO health and climate change survey report: Tracking global progress (No. WHO/CED/PHE/EPE/19.11). World Health Organization. https://apps.who.int/iris/bitstream/handle/1 0665/329972/WHO-CED-PHE-EPE-19.11-eng.pdf?ua= $1 \&$ ua $=1$.

World Wildlife Fund (WWF) (2018). Living Planet Report 2018. World Wildlife Fund, USA.

Wu, D., Fei, L., Zhang, Z., Zhang, Y., Li, Y., Chan, C., Wang, X., Cen, C., Li, P. and Yu, L. (2020). Environmental and health impacts of the change of NMHCs caused by the usage of clean alternative fuels for vehicles. Aerosol Air Qual. Res., doi: 10.4209/aaqr.2019.09.0459.
Xiang, Q.C., Feng, X.P., Jia, X.Y., Cai, L. and Chen, R. (2019). Reducing carbon dioxide emissions through energysaving renovation of existing buildings. Aerosol Air Qual. Res. 19: 2732-2745. doi: 10.4209/aaqr.2019.10.0503.

Yu, X., Geng, Y., Dong, H., Fujita, T. and Liu, Z. (2016). Emergy-based sustainability assessment on natural resource utilization in 30 Chinese provinces. J. Cleaner Prod. 133: 18-27.

Yuan, H., Zhou, P. and Zhou, D. (2011). What is low-carbon development? A conceptual analysis. Energy Procedia 5: 1706-1712.

Zhou, N. and Williams, C.J. (2013). An international review of eco-city theory, indicators, and case studies. Lawrence Berkeley National Laboratory. https://eta-publications.lbl. gov/sites/default/files/lc_eco-cities.pdf.

Received for review, November 8, 2019

Revised, February 14, 2020

Accepted, February 16, 2020 